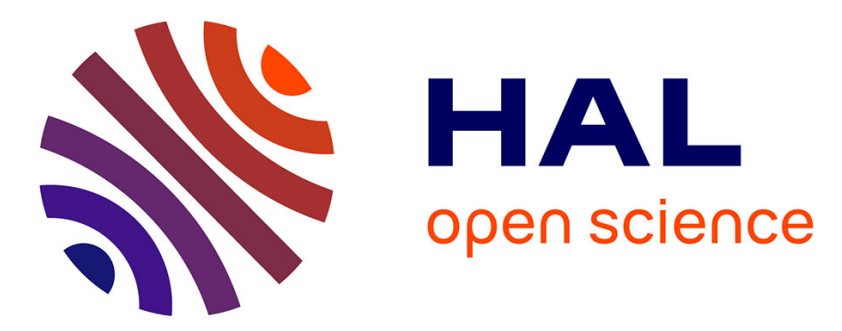

\title{
Design aspects of poly(alkylcyanoacrylate) nanoparticles for drug delivery
}

Christine Vauthier, Denis Labarre, Gilles Ponchel

\section{To cite this version:}

Christine Vauthier, Denis Labarre, Gilles Ponchel. Design aspects of poly(alkylcyanoacrylate) nanoparticles for drug delivery. Journal of Drug Targeting, 2007, 15 (10), pp.641 - 663. 10.1080/10611860701603372 . hal-03194498

\section{HAL Id: hal-03194498 \\ https://hal.science/hal-03194498}

Submitted on 9 Apr 2021

HAL is a multi-disciplinary open access archive for the deposit and dissemination of scientific research documents, whether they are published or not. The documents may come from teaching and research institutions in France or abroad, or from public or private research centers.
L'archive ouverte pluridisciplinaire $\mathbf{H A L}$, est destinée au dépôt et à la diffusion de documents scientifiques de niveau recherche, publiés ou non, émanant des établissements d'enseignement et de recherche français ou étrangers, des laboratoires publics ou privés. 


\title{
Design aspects of poly(alkylcyanoacrylate) nanoparticles for targeted drug delivery
}

\author{
Christine Vauthier ${ }^{1,2^{*}}$, Denis Labarre ${ }^{1,2}$, Gilles Ponchel ${ }^{1,2}$.
}

${ }^{1}$ CNRS, UMR 8612, Chatenay-Malabry, F-92296

${ }^{2}$ Univ. Paris Sud, UMR CNRS 8612, IFR 141, Chatenay Malabry, F-92296

Published in: J Drug Target. 2007;15(10):641-63. doi: 10.1080/10611860701603372.

\section{*corresponding authors :}

Christine VAUTHIER, phone : 331468356 03,E-mail : christine.vauthier@u-psud.fr, Physico-chimie, Pharmacotechnie et Biopharmacie, UMR CNRS 8612, Université de Paris Sud, Faculté de Pharmacie, 92296 CHATENAY-MALABRY Cedex France ;

\begin{abstract}
Poly(alkylcyanoacrylate) nanoparticles were first developed 25 years ago taking advantage of the in vivo degradation potential of the polymer and of its good acceptance by living tissues. Since then, various poly(alkylcyanoacrylate) nanoparticles were designed including nanospheres, oil-containing and water-containing nanocapsules. This made possible the in vivo delivery of many types of drugs including those presenting serious challenging delivery problems. Poly(alkylcyanoacrylate) nanoparticles were proven to improve treatments of severe diseases like cancer, infections, and metabolic disease. For instance, they can transport drugs accross barriers allowing delivery of therapeutic doses in difficult tissues to reach including in the brain or in multidrug resistant cells. This review gives an update on the more recent developments and achievements on design aspects of poly(alkylcyanoacrylate) nanoparticles as delivery systems for various drugs to be administered in vivo by different routes of administration.
\end{abstract}

Key words: drug carrier, poly(alkylcyanoacrylate), nanoparticle, nanosphere, nanocapsules, nanoparticle surface, in vivo fate 


\section{INTRODUCTION}

The interest of nanomedecine is huge and has led to intense research and development during the last 3 decades. It represents a unique opportunity to address many of the delivery problems encountered with both old and new therapeutic compounds. Innovations were made possible for the administration of challenging drugs including those with severe systemic toxicity or which are either poorly soluble or in vivo unstable [Alonso et al., 2004, Wissing et al., 2004, Mayer, 2005, Pegro et al., 2005, Moghimi et al., 2006, Pinto-Reis et al., 2006, Torchilin, 2006, Toub et al., 2006, Vauthier and Couvreur 2006, Vyas et al., 2006, Vauthier and Couvreur Submitted]. Today, it clearly appears that the potential application of nanomedecine concerns all types of the major health threats such as cancers, severe infections, metabolic diseases and autoimmune diseases which include numbers of patients and represent an important potential market for the pharmaceutical industry [Conti et al., 2006, Couvreur and Vauthier 2006]. Nanomedecine is in the process of revolutionizing diagnosis and treatments of severe diseases [Brigger et al., 2002a, Sonvico et al., 2005, Dufour-Lamartinie et al., 2006, Minko et al., 2006, Mitra et al., 2006, Roy and Perez, 2006, Sinha et al., 2006].

Milestones making these technologies a success were the development of suitable nanosystems able to bypass many of the anatomic and physiologic barriers allowing delivery of the therapeutic agents more efficiently in the targeted diseased tissues and cells hence promoting therapeutic response while minimizing side effects of the drug (Florence, 2004, Kreuter, 2004, Kommareddy et al., 2005, Olivier 2005, Csaba et al., 2006). Among the different systems proposed so far, polymer nanoparticles are accounted among the most promising drug carrier alternative to liposomes already widely used in clinics for treatments of cancer, leishmaniosis and fungal infections (Vauthier et al., 2003a, Barratt, 2004, Couvreur and Vauthier PR2006, Fattal et al., 2007). For that matter, the very active developments in this field have let poly(alkylcyanoacrylate) (PACA) nanoparticles to appear in clinics for the treatment of cancer (Kattan et al. 1992, Dufour-Larmartinie et al. 2006).

The aim of the present review paper is focus on design aspects of PACA nanoparticles for targeted drug delivery. This will include the more advanced works on the synthesis and developments of nanoparticles made of PACA for the administration of drugs by intravenous and oral routes and for local administration.

\section{SYNTHESIS OF POLY(ALKYLCYANOACRYLATE) NANOPARTICLES.}

As explained in this part of the paper, different kinds of nanoparticles made of PACA can be synthesized (Figure 1). The most straightforward methods of preparation are based on the polymerization of the corresponding monomers [Vauthier et al., 2002, 2004]. These can be used to prepare either nanospheres, i.e. plain particles, or nanocapsules, i.e. reservoir type particles. Nanospheres and nanocapsules can also be obtained from preformed PACA polymers. Strategies used for designing their surface properties will also be pointed out in the different paragraphs explaining the methods of PACA nanoparticle preparations because they appear to be critical controlling the in vivo fate of the delivery system. 


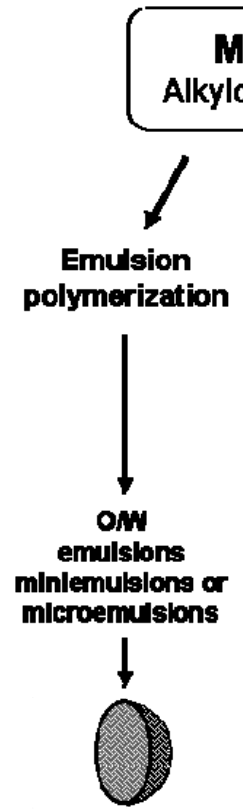

NS
Monomers Alkylcyanoacrylates
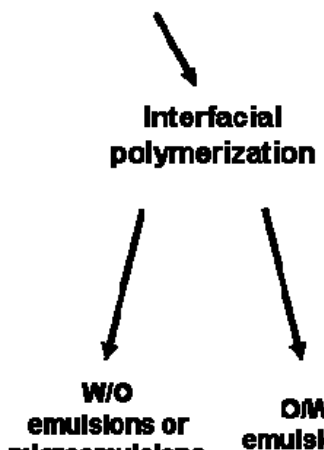

miaroemulsing

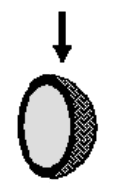

w-NC

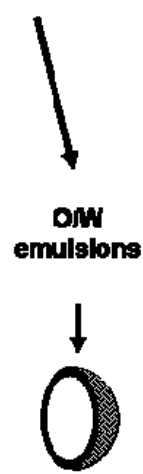

o-NC

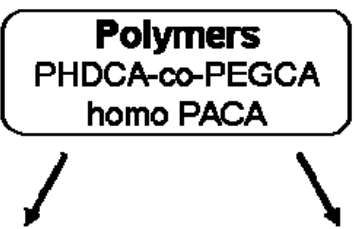

Emulsification-

Nanoprecipitation

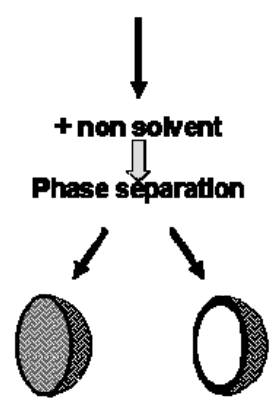

(polymer solution in organic solvents)

oNC

Solvent evaporation

(ON emulsion

with polymer dissolved in voletile orgenic solvent)

NS

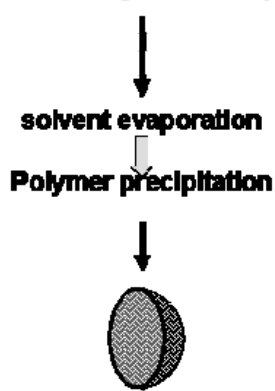

NS

Figure 1: Different methods for the preparation of poly(alkylcyanoacrylate) nanoparticles. NS: nanospheres, o-NC: oil-containing nanocapsules, w-NC: water-containing nanocapsules.

\subsection{Synthesis of nanospheres by emulsion polymerization of alkylcyanoacrylate}

Alkylcyanoacrylates are highly reactive monomers. Their anionic polymerization can be initiated by weak bases such as hydroxyl groups of the water and by any nucleophilic group containing compounds. PACA nanospheres can easily be obtained by polymerization of the monomer in an emulsion, a miniemulsion or a microemulsion. According to the polymerization medium characteristics, the polymerization of the alkylcyanoacrylates can be initiated by one of the two following mechanisms defining the polymer growing species: anionic or redox radical mechanisms. Typical recipes for anionic and redox radical emulsion polymerizations are given in table 1. In both cases, the polymerization medium is prepared from acidified water in which a compound ensuring the stability of the nascent polymer nanoparticles is dissolved. Polymerization starts immediately after the monomer is added in the polymerization medium under strong magnetic stirring. The acidic medium is necessary slowing down the anionic polymerization of alkylcyanoacrylates hence promoting formation of nanoparticles instead of polymer aggregates.

Table 1: Conditions for the preparation of PACA nanoparticles by emulsion polymerization [Bertholon et al., 2006a, $b, d$ ]

\begin{tabular}{|l|l|l|}
\hline Ingredients & Anionic emulsion polymerization & $\begin{array}{l}\text { Redox radical emulsion } \\
\text { polymerization }\end{array}$ \\
\hline Dextrane & $0.05 \mathrm{~g}$ & $0.137 \mathrm{~g}$ \\
\hline Polymerization medium & $10 \mathrm{ml}, \mathrm{pH} 2.5$ with $\mathrm{HCl}$ & $\begin{array}{l}10 \mathrm{ml}, \mathrm{pH} 1 \text { with } \mathrm{HNO}_{3} 0.2 \mathrm{~N}+ \\
\mathrm{Ce}^{\mathrm{IV}}\left(\mathrm{NH}_{4}\right)_{2}\left(\mathrm{NO}_{3}\right)_{6} 1.6 \times 10^{-2} \mathrm{M}\end{array}$ \\
\hline Conditions & $\begin{array}{l}\text { room temperature, strong } \\
\text { magnetic stirring }\end{array}$ & $\begin{array}{l}40^{\circ} \mathrm{C}, \text { nitrogen bubbling for } 10 \\
\text { min, strong magnetic stirring }\end{array}$ \\
\hline $\begin{array}{l}\text { Monomer } \\
\text { added drop wise }\end{array}$ & $0.1 \mathrm{ml}$ & $0.5 \mathrm{ml}$ \\
\hline Time of polymerization & 3 hours & 1 hour \\
\hline
\end{tabular}


In case of the anionic polymerization, the $\mathrm{pH}$ of the emulsion is generally adjusted 2.5 with hydrochloric acid. Polymerization of the monomer occurs rapidly as being initiated either by the hydroxyl groups of water, or by the nucleophilic groups borne by the stabilizing agents and sometimes by the active ingredient to be incorporated in the nanoparticles. Generaly, the polymerization is completed within 3 to 4 hours depending on whether the monomer is iso-, $n$ butyl cyanoacrylate or isohexylcyanoacrylate. Different stabilizing agents can be used to stabilize the nanoparticles [Couvreur et al., 1979, Douglas et al., 1985, Gasco and Trotta, 1986, Seijo et al., 1990, Perrachia et al., 1997a, Yang et al., 2000, Limouzin et al., 2003, Weiss et al., 2007]. Those containing nucleophilic groups can initiate the polymerization of alkylcyanoacrylates resulting in the formation of amphiphilic copolymers responsible for the stabilization of the nascent polymer nanoparticles [Douglas et al., 1985, Perracchia et al., 1997a, b, Bertholon et al., 2006a]. Size of the nanoparticles can be adjusted from 250 to $40 \mathrm{~nm}$ by varying the concentration of the added surfactant such as Pluronic between 0 and $2 \%$ respectively [Seijo et al., 1990]. When using chitosan, a positively charged polysaccharide, important factors in controlling the mean diameter of the nanoparticles are the concentration in chitosan in the reaction medium and the molecular weight of the macromolecule [Yang et al., 2000]. Thus, nanoparticles with diameter ranging from 10 to $326 \mathrm{~nm}$ can be prepared by varying these parameters. [Yang et al., 2000, Bravo Osuna et al., 2007a]. In contrast, when using dextran, a neutral polysaccharide, as the stabilizing agent, the diameter of the nanoparticles which is around $160 \mathrm{~nm}$ is not affected by the molecular weight of the polysaccharide [Bertholon et al., 2006b].

As mentioned above, the anionic polymerization of the alkylcyanoacrylate in the conditions used to prepare the nanoparticles can be initiated by compounds added to the polymerization medium. This was used to associate chemicals with the nanoparticles such as complexing agents for radio labelling purpose and radio therapy and for the association of naphtalocyanines and photosensibilizers used in phototherapy of tumors [Labib et al., 1991, Ghanem et al., 1993].

Such a reaction may also be useful to adjust nanoparticle surface properties. For instance, polysaccharides added as stabilizing agent are able to react with the monomer forming an amphiphilic copolymer composed of a single polysaccharide chains on which several pendant PACA low molecular weight chains are grafted [Bertholon et al., 2006a]. Stability of the nanoparticle dispersion is due to the presence of such a copolymer exposing the polysaccharide part on the nanoparticle surface in contact with the aqueous continuous phase of the emulsion (Figure 2). Indeed, a strong anchorage of the hydrophilic polysaccharide chains on the nanoparticle surface is obtained by the presence of the hydrophobic PACA chains of the copolymers constituting the core of the nanoparticle. By such a method, nanoparticles with different surface properties can be prepared by varying the nature of the polysaccharide or by using blends of polysaccharides [Yang et al., 2000, Labarre et al., 2005, Bertholon et al., 2006b, Bravo et al., 2007a]. For instance, zeta potential of nanoparticles prepared with dextran is ranging between $-5 \mathrm{mV}$ and $-27 \mathrm{mV}$ depending on dispersion medium [Perracchia et al., 1997b, Bertholon et al., 2006b], and zeta potential of the nanoparticles prepared with chitosan is clearly positive with values ranging from +22 to $+39 \mathrm{mV}$ [Yang et al., 2000, Bertholon et al., 2006b, Bravo Osuna et al., 2007a]. When chitosan and chitosan derivatives were used to produce positively charged nanoparticles, the $\mathrm{pH}$ of the polymerization medium was decreased to 1 in order to further reduce reactivity of the monomer hence improving chance to form nanoparticles [Yang et al., 2000, Bravo Osuna et al., 2007a]. 


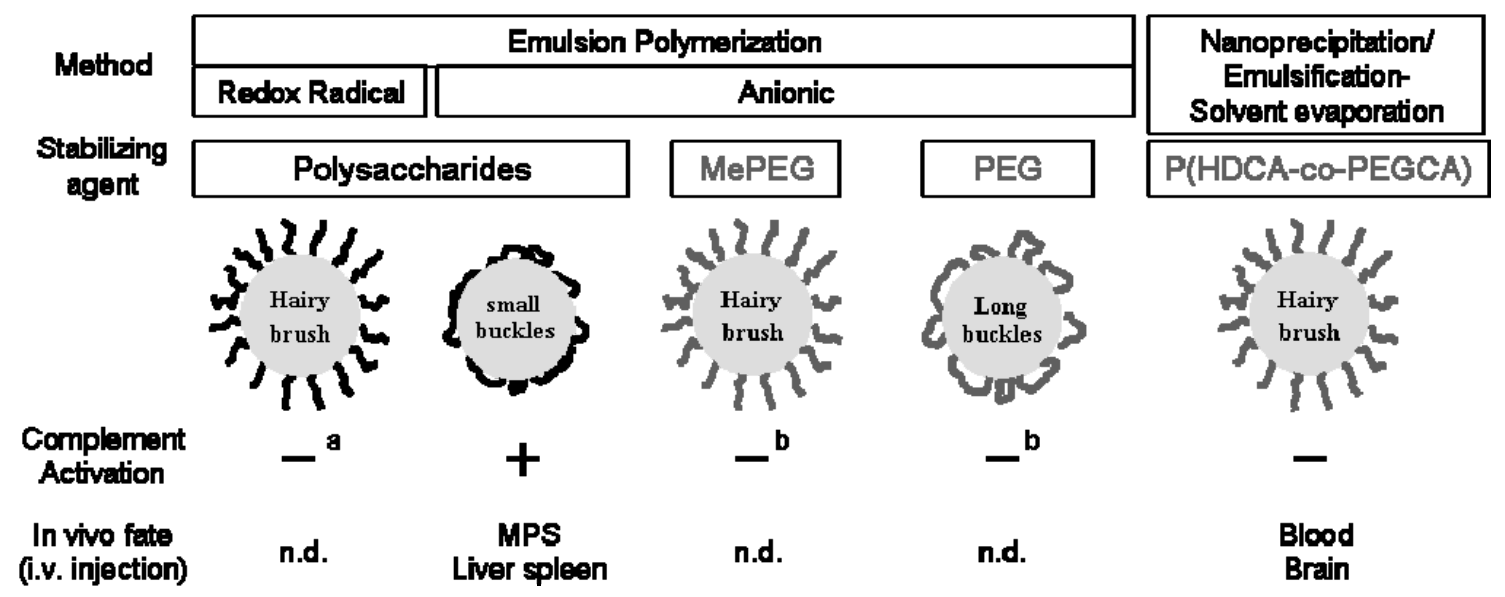

Figure 2: Spacial arrangement of polysaccharide or PEG chains at the nanoparticle surface depending on the method of nanoparticle synthesis and consequences on complement activation of serum proteins and in vivo fate of the nanoparticles. a: no complement activation was measured with nanoparticles coated with polysaccharides of a minimal molecular weight which also depended on the nature of the polysaccharide [Bertholon et al., 2006b]. b: further complement activation reduction was observed with the nanoparticles coated with prepared with PEG compared to MePEG [Perracchia et al., 1997b]. n.d.: not yet determined

Nanoparticles coated with poly(ethylene glycol) chains in different conformations were also prepared by this method using either poly(ethylene glycol) (PEG) or mono-methoxymethyl poly(ethyleneglycol) (MePEG) [Perracchia et al., 1997b]. In this case, the stabilizing amphiphilic block copolymers formed between PEG and PACA result from the initiation of the polymerization of the alkylcyanoacrylate monomer by the free hydroxyl group(s) located at the chain end(s) of the PEG or MePEG. PEG chains containing two hydroxyl groups, one at each chain end, are present as long loops at the nanoparticle surface because they are attached by two PACA anchor chains at the nanoparticle surface (Figure 2). Conversely, MePEG chains having a single free hydroxyl group per chain are forming hairy nanoparticles with PEG chains attached by only one PACA anchor chain at the nanoparticle surface (Figure 2). By coating the nanoparticle surface with PEG, the zeta potential of the nanoparticles shows rather neutral values around $6 \mathrm{mV}$ [Perracchia et al., 1997b].

Although the reaction of the different components added to the polymerization medium can be taken as an advantage as it was explained above, it can constitute an obstacle which may compromise the application of the technique. This was reported twice when the added therapeutic compounds, vidarabine and phenylbutazone, loose their biological activity [Guize et al., 1990, Galardo et al. 1989].

Poly(n-butylcyanoacrylate) nanosphere dispersions with high solid contents, i.e. up to $10 \%$, were prepared by polymerizing the monomer in a miniemulsion [Weiss et al., 2007]. In this method, the monomer is dispersed in an aqueous phase at $\mathrm{pH} 1$ with hydrochloric acid using ultrasounds. Once the miniemulsion is formed, the polymerization is initiated by adding sodium hydroxyde or a nucleophilic compound such an amino acid. The diameter of the nanoparticles can be tuned from 80 to $350 \mathrm{~nm}$ varying the concentration of sodium dodecyl sulphate used as surfactant and the nature of the polymerization initiator. As already discussed above, functionalized nanoparticles can be obtained by this method by initiating the polymerization with various nucleophilic compounds. 
A second type of polymerization can be used to produce nanoparticles possessing a PACA core and a polysaccharidic shell. This polymerization is a redox radical polymerization initiated by the couple polysaccharide-cerium IV ions. As the anionic polymerization is very fast even at $\mathrm{pH} 2.5$, redox radical polymerization can only occur at a faster rate in $0.2 \mathrm{M}$ nitric acid. In such a condition, the spontaneous anionic polymerization is frankly delayed giving a time window for making possible initiation and chain growing through the redox radical polymerization mechanism [Chauvierre et al., 2003a]. During polymerization, a linear block copolymer including one chain of polysaccharide and one chain of PACA is formed [Bertholon et al., 2006a]. This copolymer shows amphiphilic properties giving nanoparticle suspensions stable over 3 years. Nanospheres with a wide range of diameter can be prepared by this method. The size of the nanospheres varying from 80 to $600 \mathrm{~nm}$ is partly controlled by the molecular weight of the polysaccharide but a minimum value of the molecular weight is required to achieve stability of the nanosphere dispersion [Bravo-Osuna, 2007a, Bertholon et al., 2006b]. This minimum value was found around $6,000 \mathrm{~g} / \mathrm{mol}$ for most polysaccharides. Using polysaccharides with very high molecular weights $\left(10^{6} \mathrm{~g} / \mathrm{mol}\right)$, microspheres can be obtained [Chauvierre et al., 2003b]. The size of the nanoparticles also depends on the nature of the polysaccharides. Compared with dextran (nanoparticles having diameter lower than $300 \mathrm{~nm}$ ), bigger nanoparticles, i.e. diameter from 350 to $600 \mathrm{~nm}$ ) are obtained with charged polysaccharides such as dextran sulphate or chitosan [Bertholon et al., 2006b]. However, small nanoparticles, i.e. diameter $80 \mathrm{~nm}$, can be obtained with heparin [Chauvierre et al., 2003b]. The nanoparticle surface properties are strongly dependent on the nature and the molecular weight of the polysaccharide used for the synthesis since the polysaccharide part of the copolymer is exposed at the nanoparticle surface. It is note worthy to point out that the conformation of the polysaccharide chains at the nanoparticle surface is very different from the conformation of the polysaccharide chains standing at the surface of nanoparticles produced by the anionic polymerization (Bertholon et al., 2006a) (Figure 2). This is due to the structure of the copolymer produced by this polymerization because the polymerization of alkylcyanoacrylate is initiated here at one chain end of the polysaccharide. Thus, each polysaccharide chain has a single anchorage point at the nanoparticle surface, resulting in formation of hairy nanoparticles (Figure 2). It is also noteworthy to mention that polysaccharide biological properties are preserved during nanoparticle preparation confering the nanoparticle surface with new interesting biological properties. The zeta potential of these nanospheres was clearly defined by the type of polysaccharide involved during their synthesis. It could be either positive $(+27 \mathrm{mV})$, negative $(-45 \mathrm{mV})$ or rather neutral $(-12 \mathrm{mV})$ depending on whether the nanospheres were prepared with chitosan, dextran sulphate, heparin or dextran respectively [Labarre et al., 2005, Bertholon et al., 2006b, Bravo Osuna et al., 2007a]. An intermediate value $(-24 \mathrm{mV})$ was obtained for nanoparticles prepared from a blend of heparin and dextran [Labarre et al., 2005].

\subsection{2. Synthesis of nanospheres from preformed polymers}

PACA nanospheres can also be obtained from preformed polymers (Figure 1). The methods used for these preparations are based on nanoprecipitation or solvent diffusion process or on the emulsification-solvent evaporation procedure. In both cases, the polymer is a copolymer of poly(hexadecylcyanoacrylate-co-poly(MePEG) cyanoacrylate) (P(HDCA-co-PEGCA)) which is synthesized by reaction of alkylcyanoacetic acid and MePEG cyanoacetic acid with formaldehyde in the presence of catalysts according to a Knoevenagel reaction [Perracchia et al., 1997c]. Such a copolymer is amphiphilic showing hydrophilic moieties given by the pendant MePEG chains and hydrophobic moieties given by the hexadecyl chains of the 
hexadecylcyanoacrylate residues incorporated in the polymer chain. The copolymer, which is soluble in organic solvents but insoluble in water, can be dissolved in the most popular solvents used in procedures of nanosphere preparations using preformed polymers [Harris, 1992, Perracchia et al., 1997c, Brigger et al., 2000,].

For preparing nanospheres by nanoprecipitation, the copolymer is dissolved in a water miscible solvent (THF or acetone) which is then poured in an aqueous phase. Monodispersed nanospheres with a diameter around $100 \mathrm{~nm}$ are formed [Perracchia 1998]. The low polydispersity obtained with this method can be explained by the fact that polymer particles are nucleated readily when the polymer solution is poured in the aqueous phase in which the polymer is insoluble [Ganachaud and Katz, 2005]. Thus, nanoparticles are all formed in the same conditions reducing polydispersity of the nanoparticle size. Because of the amphiphilic properties of the copolymer, there is no need to add surface active agent in these preparations.

Preparation of nanospheres by the emulsification-solvent evaporation method requires that the copolymer is dissolved in a non water miscible organic solvent, typically ethyl acetate or methylene chloride. The polymer solution is then emulsified in an aqueous phase. The removal of the organic solvent from the emulsion droplets of the dispersed phase by evaporation induces precipitation of the polymer and lead to the formation of nanospheres. In general, the size of the nanospheres depends on the size of the emulsion droplets. This means that to obtain small nanospheres it is necessary to prepare very thin emulsions. This can be achieved by using special equipments including high pressure homogenizers, microfluidizers or colloidal mills. Additionally, it was reported in the literature in a study considering other poly(acrylates) that the size of the emulsion droplets depends on the viscosity of the polymer solution which in turn depends on concentration and molecular weight of polymers [Desgouilles et al., 2003]. In the case of the preparation of the nanospheres with the copolymer of P(HDCA-Co-PEGCA), addition of a surfactant is not necessary because the copolymer is amphiphilic and acts as a surfactant by itself. The size of the nanospheres prepared by this method is ranging between 100 and 200nm [Perachia et al., 1998]. The polydispersity of the dispersion was generally higher than polydispersity obtained in the case of nanospheres prepared by nanoprecipitation.

Surface properties of the $\mathrm{P}(\mathrm{HDCA}-\mathrm{Co}-\mathrm{PEGCA})$ nanospheres prepared from the preformed polymer are given by the PEG hydrophilic part of the copolymer [Peracchia et al., 1998]. Due to the comb-brush structure of the synthesized copolymer, the PEG chains form a brush like structure at the nanosphere surface (figure 2). Moreover, the surface of the nanospheres can be functionalized by using a copolymer containing an amino-terminated PEG moiety. This allows the covalent linkage of ligands at the nanoparticle surface which can be used as specific targeting moieties allowing recognition of the drug carrier by the targeted cells [Stella et al., 2000]

\subsection{3. Synthesis of nanocapsules by interfacial polymerization of alkylcyanoacrylate}

Nanocapsules differ from nanospheres in that they are a reservoir form, in which a thin polymer shell surrounds a liquid core. In the first nanocapsule formulations, the core was composed of oil hence allowing a high payload of a liposoluble drug encapsulation. Nanocapsules with an aqueous core able to encapsulate water-soluble compounds were developed more recently. The content of the nanocapsules is determined by the nature of the dispersed phase of the emulsion or of the microemulsion constituting the basis of the formulation (Figure 1). Generally, the polymer shell surrounding the liquid core is formed thanks to the spontaneous anionic polymerization of alkylcyanoacrylates taking place at the 
interface between the dispersed and continuous phase of the emulsion [Al Khouri et al., 1986, Vrancks et al., 1996, Lambert et al., 2000a, Wohlgemuth et al., 2003, Mayer, 2005, Hillaireau et al. JCR 2006a, Watnasirichaikul et al., 2002a].

To prepare oil-containing nanocapsules, the oil and the monomer are first dissolved in a watermiscible solvent such as ethanol in which the monomer is then added. This organic phase is poured in a surfactant containing aqueous solution under magnetic stirring. Generally, the surfactant used in the aqueous phase is Poloxamer 188. As the organic phase diffuses into the water, the oil is dispersed as fine droplets and polymerization of the alkylcyanoacrylate monomers occurs at the interface, initiated by nucleophilic groups such as the hydroxyl ions of water. A wide range of oils can be incorporated in the organic phase, ranging from vegetal and mineral oils to pure compounds including ethyl oleate, the principal criterium of choice being the solubility of the compound to be encapsulated in the nanocapsules. A lipophilic surfactant, often soya lecithin, may be added to the organic phase.

The most important factors which lead to the structure of nanocapsules are the phase separation of the oil droplets occurring during the diffusion of the water miscible organic solvent in the aqueous phase and the simultaneous precipitation of the polymer at the interface formed between the oily droplets and the aqueous phase [Gallardo et al. 1993]. One problem encountered with this method is the contamination of the nanocapsule dispersions with nanospheres. Reduction of this contamination can be obtained by optimizing the ethanol/oil ratio and by inhibiting polymerization initiation occuring in the organic phase [Gallardo et al., 1993, Aboubakar et al., 1999]. Indeed, the technique can be improved by acidifying ethanol adding hydrochloric acid. This limits the extend of the polymerization to the formation of ethanol-single monomer adduct [Wohlgemuth et al., 2003]. Another improvement can be obtained by replacing ethanol by aprotic solvents such as acetone and acetonitrile which are not able to initiate the polymerization reaction [Puglisi et al., 1995].

The mean diameter of nanocapsules with an oily core formed by interfacial polymerization is usually found to be between 200 and $350 \mathrm{~nm}$ and depends on several factors: the nature and the concentration of the monomer and encapsulated drug, the amount of surfactant, the volume fraction of the dispersed phase, the concentration of oil in the organic solution or the speed of diffusion of the organic phase in the aqueous phase. When the preparation is performed in a mini-emulsion instead of an emulsion, nanocapsules with diameter lower than $100 \mathrm{~nm}$ can be prepared. The nanocapsule size obtained in this case is independent of the volume fraction of the dispersed phase. This means that one can increase the concentration in nanocapsules in the final suspension simply by increasing the volume fraction of the dispersed phase in the starting mini-emulsion without changing the size characteristics of the nanocapsules recovered at the end of the preparation [Altinbas et al., 2006].

Water-containing nanocapsules are mostly prepared from inverse emulsions and inverse microemulsions [Vranckx et al., 1996, Lambert et al., 2000a, Watsanirichaikul et al., 2002a, Krauel et al. 2005, Hillaireau et al., 2007]. Generally, the emulsions or the microemulsions are prepared by using non-ionic surfactants, i.e., blends of sorbitan monooleate and polysorbate, and without the monomer which is added to the continuous phase after preparation of the formulation. Spontaneous anionic polymerization of the monomer occurs at the surface of the water droplets to form a thin polymer film surrounding the aqueous droplets of the emulsion or of the microemulsion which constitute the core of the nanocapsules. Indeed, the anionic polymerization of the monomers can be initiated by the hydroxyl groups of the water molecules and by any kinds of nucleophilic group containing components standing at the water droplet interface such as surface-active agents. The nanocapsules with an aqueous core prepared with non-ionic surfactants have a mean diameter ranging from 250 to $350 \mathrm{~nm}$ 
[Lambert et al., 2000a, Krauel et al., 2005, Hilaireau et al., 2007]. The smallest aqueous containing nanocapsules having a diameter of $50 \mathrm{~nm}$ can be obtained with poly(ethyleneoxide) lauryl ester (Brij 35) while the formulation of the inverse emulsion with an anionic surfactant led to the formation of nanocapsules with diameter around 300nm [Vranckx et al., 1996]. In the final preparation, aqueous containing nanocapsules are dispersed in oil because they are obtained from inverse emulsions or microemulsions. Although such dispersion can be administered by the oral route, it is absolutely not suitable for intravenous injections. Lambert et al., 2000a have suggested a method to transfer the nanocapsules from the oil dispersing medium into an aqueous continuous phase. This method is based on the ultracentrifugation of the initial dispersion over a layer of the new aqueous dispersion phase so that transfer of the nanocapsules occurs through the interface between the oil and the aqueous media reducing the risk of nanocapsule aggregation. The technique was recently improved by Hillaireau et al. 2007.

According to zeta potential measurements, surface properties of nanocapsules are given by surfactant used to prepare the polymerization medium. Generally, these surfactants contain PEG hydrophilic moieties and the physico-chemical surface properties shown by the nanocapsules agrees with those of polymer particles stabilized with such surfactants. There is no influence of the other component of the formulation indicating that encapsulated compounds are mostly incorporated in the nanocapsule liquid core [Aboubakar et al., 1999, Hillaireau et al., 2007, Lambert et al.2000a].

\subsection{4. Synthesis of nanocapsules from preformed polymers}

Poly(alkcyanoacrylate) nanocapsules can be synthesized by interfacial deposition or nanoprecipitation of preformed polymers like the homopolymer of PACA or the copolymer of P(HDCA-co-PEGCA) [Barratt et al., 1994, Brigger et al., 2003, Mayer, 2005]. The synthesis of the copolymer was briefly described above (see paragraph 2.2). The homoPACA can be prepared in a very simply way by dripping the corresponding monomer in pure water. The precipitated polymer which is formed is then recovered as a white powder by lyophilization. To prepare the nanocapsules, the polymer is dissolved in an organic phase containing acetone and a small amount of the oil which will constitute the liquid core of the nanocapsules. When the acetone polymer solution is poured in the aqueous phase, the nanocapsules form instantaneously by deposition of the polymer which precipitates as a thin film surrounding the oil droplet. In general, the aqueous solution contains a surfactant when the nanocapsules are prepared from the homopolymer. In contrast, there is no need adding a surfactant in the preparation medium of nanocapsules prepared from the copolymer. At the end of the preparation, acetone is removed from the nanocapsules dispersion by low pressure rotary evaporation. The size of the nanocapsules prepared by this method is usually ranging from 150 to $200 \mathrm{~nm}$ [Brigger et al., 2003].

Water containing nanocapsules can be obtained from a double emulsion by the emulsificationsolvent evaporation technique. In this case, the polymer, P(HDCA-co-PEGCA), is dissolved in methylene chloride and the solution constitute the intermediate phase of the water-in-oil-inwater double emulsion. The polymer wall forms around the water droplets of the inner phase when the polymer precipitates due to the evaporation of methylene chloride [ $\mathrm{Li}$ et al., 2001a,b]. 


\section{LOADING POLY(ALKYLCYANOACRYLATE) NANOPARTICLES WITH DRUGS}

Almost all kinds of drugs have been associated with success with PACA nanoparticles (table 2). They include small hydrosoluble and poorly soluble molecules, peptides, proteins and different kinds of nucleic acids like nucleosides, oligonucleotides and small interfering RNA. This can be explained by the fact that different types of nanoparticles can be prepared leading to a large choice of methods to achieve the encapsulation of therapeutically active substances. Low molecular weight chemical compounds including many anticancer agents, anti-infectious molecules and anti-inflammatory compounds, were associated with nanospheres (Table 2). The association of more sophisticated drug molecules like peptides and oligonucleotides or siRNA with PACA drug carriers was more often considered in nanocapsules instead of nanospheres.

\subsection{1. Incorporation of drugs in nanospheres}

Generally, drugs to be incorporated in nanospheres are dissolved in the polymerization medium. This is typically the case for hydrosoluble molecules such as doxorubicine, ampicillin, fluoroquinolone and ciprofloxacine given as exemples. Although this approach was successful with most of the tested molecules, one should keep in mind that the alkylcyanoacrylate monomers are highly reactive compounds and can react with any kind of active ingredient showing nucleophilic groups in their structure. Such possible side reactions can be used to promote association of drugs with the nanoparticles by covalent binding. For instance, such an approach was applied to naphtalocyanines which are photosensibilizers used in phototherapy of tumors [Labib et al., 1991] and to a serie of molecules containing di-ethyl triamine pentacetic acid able to form complexes with radioactive metals radiolabelling the nanospheres for applications in medical imaging techniques [Ganhem et al., 1993]. However, such side reactions may also compromise the activity of the drug or the formation of nanospheres. For instance, covalent linkage of the monomer to phenylbutazone and to vidarabine led to the loss of the biological activity of these compounds (Gallardo et al., 1989, Guize et al., 1990). Although such a reaction was clearly demonstrated with these two compounds, they were the only cases reported in the literature so far. The incorporation of growth hormone, a peptide, in the polymerization medium induced uncontrolled polymerization of alkylcyanoacrylate leading to formation of aggregates instead of well characterized nanospheres. This second type of side reactions could be avoided by adding the peptide after the polymerization have been started by the addition of the monomer (Grangier et al., 1991). A delay between the addition of the monomer and the addition of the peptide of 10 to 20 min was found optimal to obtain good rates of association of the peptide with the drug carrier and satisfactory characteristics of the nanospheres.

Association of poorly water-soluble molecules with PACA nanospheres appeared more problematic. However, cyclodextrins added to the polymerization medium can be used to promote drug association with the nanospheres by increasing the drug solubility in the polymerization medium (Monza Da Silveira et al., 1998, Duchene et al., 1999). Additionaly, large cyclodextrins amounts are likely to be associated to the particles, making again possible to increase tremendously drug loadings. This strategy was applied for association of various steroids, saquinavir, an antiprotease of HIV agent, and paclitaxel, a lead product in cancer therapy. 
Table 2: Drugs incorporated in PACA nanoparticles. PIBCA: poly(isobutylcyanoacrylate), PBCA: Poly(n-butylcyanoacrylate), PECA: poly(ethylcyanoacrylate), PIHCA: poly(isobutylcyanoacrylate)

\begin{tabular}{|c|c|c|c|c|}
\hline Type of molecules & Examples & Activity/Application & Type of nanoparticles & references \\
\hline \multirow{18}{*}{$\begin{array}{l}\text { Sparingly soluble } \\
\text { compounds }\end{array}$} & Indomethacin & Anti-inflammatory drug & Oil containing PIBCA nanocapsules & Ammoury et al., 1991 \\
\hline & $\begin{array}{l}\text { Carbamazepine } \\
\text { Ethosuccimide } \\
\text { 5,5-diphenyl hydrantoin }\end{array}$ & Anti-epileptic drugs & Oil containing PIBCA nanocapsules & Fresta et al., 1996 \\
\hline & Vicamicin & Antitumor antibiotics & PHCA nanospheres & Maincent et al., 1986 \\
\hline & Mitoxantrone & Anticancer drug & PBCA nanospheres & $\begin{array}{l}\text { Rezak et al., } 1997 \\
\text { Zhang et al., } 1999\end{array}$ \\
\hline & Tamoxifen & Anticancer drug & PEG coated $\mathrm{P}(\mathrm{HDCA}-\mathrm{co}-\mathrm{PEGCA})$ nanospheres & Brigger et al., 2001 \\
\hline & Busulfan & Anticancer drug & PIBCA and PECA nanospheres & Layre et al., 2006 \\
\hline & Paxlitaxel & Anticancer drug & PBCA nanospheres & Huang et al., 2007 \\
\hline & $\begin{array}{l}5 \text { fluoro-1-(tetrahydro-2- } \\
\text { furyl) uracil }\end{array}$ & Anticancer drug & PECA and PBCA nanospheres & Arias et al., 2007 \\
\hline & $\begin{array}{l}\text { Phtalocyanine } \\
\text { Naphtalocyanine }\end{array}$ & Phototherapy in cancer & $\begin{array}{l}\text { PIBCA and PECA nanocapsules and } \\
\text { nanospheres }\end{array}$ & Labib et al., 1991 \\
\hline & MDP-L-Analyl cholesterol & $\begin{array}{l}\text { Immunomodulator used } \\
\text { in cancer therapy }\end{array}$ & Oil containing PACA nanocapsules & Barrat et al., 1994 \\
\hline & Acyclovir, Gancyclovir & Antiviral drug & PECA nanocapsules & El Samaligy et al., 1996 \\
\hline & Acyclovir & Antiviral drug & PEG-coated PECA nanospheres & Fresta et al., 2001 \\
\hline & Azothimidine & Antiviral drug & PHCA nanospheres & Loberberg et al., 1997 \\
\hline & Saquinavir & $\begin{array}{l}\text { Antiviral drug: HIV } \\
\text { antiprotease }\end{array}$ & $\begin{array}{l}\text { PIBCA and PIHCA nanospheres with } \\
\text { cyclodextrines }\end{array}$ & Boudad et al., 2001a, b \\
\hline & Darodipine & Antihypertensive agent & Oil-containing PIBCA nanocapsules & Hubert et al., 1991 \\
\hline & Betaxolol & Anti-glaucomatous & Oil containing PIBCA nanocapsules & Marchal-Heusler et al., 1992 \\
\hline & Pilocarpine & Anti-glaucomatous & PBCA nanospheres & Zimmer et al., 1994 \\
\hline & Pilocarpine & Anti-glaucomatous & Oil containing PIBCA nanocapsules & Desai and Blanchard, 2000 \\
\hline
\end{tabular}


Table 2 (continue)

\begin{tabular}{|c|c|c|c|c|}
\hline Type of molecules & Examples & Activity/Application & Type of nanoparticles & references \\
\hline \multirow[t]{11}{*}{$\begin{array}{l}\text { Small water-soluble } \\
\text { compounds }\end{array}$} & $\begin{array}{l}\text { Methotrexate } \\
\text { Vinblastine } \\
\text { Actinomycin } \\
\end{array}$ & Anticancer drug & PECA nanospheres & $\begin{array}{l}\text { Couvreur et al., } 1980 \\
\text { Brasseur et al., } 1980\end{array}$ \\
\hline & Doxorubicin & Anticancer drug & PIBCA, PIHCA nanospheres & $\begin{array}{l}\text { Couvreur et al., } 1982 \\
\text { Chiannilkulchai et al., 1989 } \\
\text { Colin de Verdiere et al., 1994, } 1997 \\
\text { Brigger et al., } 2004\end{array}$ \\
\hline & Penicillin V & antibiotic & PECA nanospheres & Couvreur et al., 1980 \\
\hline & Ampicillin & Antibiotic & PIHCA nanospheres & $\begin{array}{l}\text { Youssef et al.,1988, } \\
\text { Fattal et al., 1989, } 1991\end{array}$ \\
\hline & Primaquine & Anti parasitic agent & PIHCA nanospheres & Gaspar et al., 1992 \\
\hline & Dehydroemetine & Antibiotic & PIHCA nanospheres & Fouarge et al., 1989 \\
\hline & $\begin{array}{l}\text { Ofloxacin } \\
\text { Perfloxacin mesilate }\end{array}$ & antibiotic & PECA nanospheres & Fresta et al., 1995 \\
\hline & Ciprofloxacin & antibiotic & PIBCA nanospheres & Page-Clisson et al., 1998 \\
\hline & Nucleoside tri phospates & antiviral & Water-containing nanocapsules & Hillaireau et al. 2006a, b \\
\hline & Different model molecules & & Water-containing PECA nanocapsules & Pittaksuteepong et al., 2002 \\
\hline & cyclodextrine & Drug scavenger & PIBCA and PIHCA nanospheres & $\begin{array}{l}\text { Monza da Silva et al., 1998, } 2004 \\
\text { Duchene et al., } 1999\end{array}$ \\
\hline
\end{tabular}


Table 2 (continue)

\begin{tabular}{|c|c|c|c|c|}
\hline Type of molecules & Examples & Activity/Application & Type of nanoparticles & references \\
\hline \multirow[t]{9}{*}{ Peptides } & Insulin & Metabolic disease & PECA nanospheres & Couvreur et al., 1980 \\
\hline & Insulin & Metabolic disease & Oil containing PIBCA nanocapsules & $\begin{array}{l}\text { Damgé et al., 1988, } \\
\text { Lowe and Temple, } 1994\end{array}$ \\
\hline & Insulin & Metabolic disease & Water containing PIBCA nanocapsules & Watnasirichaikul et al., 2000 \\
\hline & Calcitonin & Metabolic disease & Oil containing PIBCA nanocapsules & Lowe and Temple, 1994 \\
\hline & Salmon calcitonin & Metabolic disease & water-containing nanocapsules & Vranckx et al., 1996 \\
\hline & $\begin{array}{l}\text { Octreoide } \\
\text { analogous) }\end{array}$ & Metabolic disease & Oil containing PIBCA nanocapsules & Damgé et al., 1997 \\
\hline & $\begin{array}{l}\text { Growth hormone releasing } \\
\text { factor }\end{array}$ & Hormone & PIBCA nanospheres & Grangier et al., 1991 \\
\hline & $\begin{array}{l}\text { Granulocyte-colony } \\
\text { stimulating factor }\end{array}$ & Hormone & PIBCA and PIHCA nanospheres & Gibaud et al., 1998 \\
\hline & Tumor necrosis factor $\alpha$ & Anticancer drug & $\begin{array}{l}\text { PEG coated } \\
\text { nanospheres }\end{array}$ & Li et et al., 2001a, b \\
\hline \multirow[t]{6}{*}{ Oligonucleotides } & Antisens antiras & Anticancer drug & CTAB-coated PIBCA nanospheres & $\begin{array}{l}\text { Chavany et al., } 1992 \\
\text { Schwab et al., } 1994\end{array}$ \\
\hline & Antisens Anti PKC $\alpha$ & & CTAB-coated PIBCA nanospheres & Lambert et al., 1998 \\
\hline & Antisense Anti EWS Fli 1 & $\begin{array}{l}\text { Anticancer drug: } \\
\text { sarcoma d'Ewing }\end{array}$ & CTAB-coated PIBCA nanospheres & Maksimenko et al., 2003 \\
\hline & Antisense Anti EWS Fli 1 & $\begin{array}{l}\text { Anticancer drug: } \\
\text { sarcoma d'Ewing }\end{array}$ & $\begin{array}{l}\text { water-containing PIBCA nanocapsules, } \\
\text { PIHCA nanospheres }\end{array}$ & $\begin{array}{l}\text { Lambert et al., 2000b } \\
\text { Maksimenko et al., } 2003 \\
\text { Toub et al., 2006c }\end{array}$ \\
\hline & siRNA anti EWS-Fli1 & $\begin{array}{l}\text { Anticancer drug: } \\
\text { sarcoma d'Ewing }\end{array}$ & water-containing PIBCA nanocapsules & Toub et al., $2006 a$ \\
\hline & siRNA anti EWS-Fli1 & $\begin{array}{l}\text { Anticancer drug: } \\
\text { sarcoma d'Ewing }\end{array}$ & Chitosan-coated PIHCA nanospheres & Maksimenko et al., 2005 \\
\hline Other compounds & Magnetite & imaging & PECA nanospheres & $\begin{array}{l}\text { Ibrahim et al., } 1983 \\
\text { Arias et al., } 2001\end{array}$ \\
\hline
\end{tabular}




\subsection{2. Incorporation of drugs in nanocapsules}

Encapsulation of drug within nanocapsules greatly depends on the drug solubility in the core material of the nanocapsules. Poorly water-soluble compounds can be encapsulated in oilcontaining nanocapsules while water-containing nanocapsules are more adapted to achieve encapsulation of hydrosoluble compounds [Fresta et al., 1996, Vranckx et al., 1997, Aboubakar et al., 1999, Watnasirichaikul et al., 2000, Cournarie et al., 2004, Hillaireau et al.,2006a, b, 2007]. There are some exceptions to this general rule. For instance, high yields of encapsulation were reported with peptides in oil-containing nanocapsules prepared by interfacial polymerization of alkylcyanoacrylate monomers. However, it was found that the yield of encapsulation depended on the molecular weigh of the peptide to be incorporated within the nanocapsules [Couvreur et al., 2002]. Indeed, very small peptides like glutathione could not be encapsulated in these systems where as somatostatin, calcitonin, octreoide and insulin having much higher molecular weight could be retain in the oil droplet constituting the core of the nanocapsules during the rapid formation of the surrounding polymer wall [Damgé et al., 1988, 1997, Lowe and Temple, 1994, Aboubakar et al., 1999]. It appears that the extremely rapid polymerization of the alkylcyanoacrylate at the surface of the oil droplet limits the diffusion of the large peptides towards the aqueous phase and therefore leads to their efficient entrapment in the nanocapsule core as demonstrated by transmission electron microscopy [Pinto Alphandary et al. 2003]. It is note worthy that peptides remained biologically active after encapsulation in the oil-containing nanocapsules [Damgé et al., 1988, 1997]. It seems that the large excess of ethanol involves during nanocapsule preparations prevent risk of side reactions between the monomer and the peptide to occur hence preserves intactness of the drug activity [Aboubakar et al. 1999].

Water-containing nanocapsules were found very suitable systems for the encapsulation of peptides and short fragments of nucleic acids, including antisens oligonucleotides and siRNA [Watnasirichaikul et al. 2000, Lambert et al. 2000a, Toub et al. 2006a, Hillaireau et al., 2007]. True encapsulation was reported with oligonucleotides which were found to be in the core of the nanocapsules [Lambert et al. 2000a]. As reported with oil-containing nanocapsules, the encapsulation of low molecular weight hydrosoluble molecules in the water-containing nanocapsules appeared compromised as well. Indeed, low molecular weight compounds including a new generation of antiviral agents obtained from nucleoside derivatives could not be easily encapsulated in the water containing nanocapsules [Hillaireau et al., 2007]. This difficulty was clearly due to the low molecular weight of nucleosides and was also reported with other types of molecules [Pitaksuteepong et al., 2002, Hillaireau et al., 2007]. A solution was found to load nanocapsules with nucleoside. It is based on the co-encapsulation of a high molecular weight polycation such as polyethyleneimine, in the nanocapsule core. The rational behind this was that nucleosides are then retained by the polycation inside the nanocapsules thanks to the formation of ion pairs [Hillaireau et al., 2006a, 2007]. This strategy which was very successful also allowed to control the release of the encapsulated nucleoside over several hours.

\subsection{3. Preparation of drugs loaded PACA nanoparticles by methods avoiding polymerizations.}

To avoid the effect of the side reactions due to the polymerization of the alkylcyanoacrylate, association of drugs can be achieved by preparing PACA nanoparticles by techniques which do not require a polymerization reaction. For instance, nanoparticles can be obtained by 
nanoprecipitation of PACA obtained by anionic polymerization (Monza da Silveira et al., 2004). So far, only a few molecules have been associated with nanoparticles prepared with the copolymer, P(HDCA-co-PEGCA). The peptide, tumor necrosis factor-alpha (TNF-alpha) was encapsulated in water containing nanocapsules prepared by emulsification-solvent evaporation from a double emulsion [Li et al., 2001a, b]. Doxorubicin and tamoxifen were incorporated in nanospheres of the same polymer by nanoprecipitation [Brigger et al., IJP 2001, Brigger et al., JCR2004, De Kozac et al., 2004].

Another possible strategy proposed to load PACA nanoparticles with their cargo avoiding polymerization reaction is based on the adsorption of the drug molecule on already prepared nanoparticles by any of the previous methods. This was used, for instance, the first-time antisense oligonucleotides were associated with PACA nanoparticles. The oligonucleotides were adsorbed via an ion-pair formation on the surface of nanospheres pre-incubated with a cationic surfactant, namely, cetyltrimethylammonium bromide (CTAB) [Chavany et al., 1992, 1994]. More recently, hemoglobin was inserted on the surface of the dextran-coated nanoparticles. The highest loading in hemoglobin was obtained with the hairy nanospheres prepared by redox-radical emulsion polymerization $(0.71 \pm 0.40 \mathrm{mg}$ of hemoglobin per $\mathrm{ml}$ of suspension, $n=11$ ) while their counterparts obtained by anionic emulsion polymerization load much less hemoglobin ( $0.23 \pm 0.28 \mathrm{mg}$ of hemoglobin per $\mathrm{ml}$ of suspension, $\mathrm{n}=5$ ) [Chauvierre et al., 2004, 2007]. The gas exchange capacity of the hemoglobin was preserved after association with the nanoparticles prepared by redox radical emulsion polymerization.

\subsection{4. Protection of drugs against degradation and release of drugs from poly(alkylcyanoacrylate) nanoparticles.}

PACA nanoparticles can protect active molecules entrapped within the structure of the particles [Damgé et al., 1988, Chavany et al., 1994, Aboubakar et al., 2000, Dembri et al., 2001, Couvreur et al., 2002, Vauthier et al., 2003a, Fattal et al., 2007]. However it is expected that the drug will be released from the drug carrier once it has reached the biological target site.

PACA are bioerodible polymers that are degraded in vivo mainly by esterases of the pancreatic juice in the intestinal tract and by serum esterases in the blood. [For more information see Vauthier \& Couvreur 2002, Vauthier et al., 2003b]. Interestingly, the degradation of PACA nanoparticles takes place in a couple of hours. Compared to other degradable polymers, the time frame of the degradation of PACA nanoparticles suits very much for many of therapeutic applications including the drug targeting strategies. This depends on the alkyl side chain length of the alkylcyanoacrylate residues composing the polymer of the nanoparticles. The degradation products (alkylalcohol and poly(cyanoacrylic acid)) are soluble in water and easily eliminated from the body through kidney filtration. In certain cases, degradation represents the major mechanism driving the release of the entrapped drug. For instance, the release of the human growth hormone from poly(isobutylcyanoacrylate) nanospheres was found to occur in parallel with the degradation of the nanospheres [Grangier et al., 1991]. Similarly, leak of insulin from nanocapsules occurred when the nanocapsules were clearly degraded in the intestinal medium [Aboubakar et al., 2000].

The releasing pattern of the drug can also greatly depend on the nanoparticle structure. This was described with low-molecular-weight substances entrapped in nanoparticles and for which releasing mechanisms involved diffusion through the polymer rather than polymer degradation. From nanospheres, drug releasing pattern can be described by kinetic models relevant to spherical matricial systems while releasing profiles of drugs from nanocapsules are better described by models considering reservoir type systems [Gallardo, 1991]. The group of 
Wohlgemuth [Wohlgemuth et al., 2003] has shown by NMR measurements that ethanol and benzene can diffuse freely through the polymer envelope of nanocapsules. However, the release can be modulated by adjusting the properties of the nanocapsule wall according to the alkyl side-chain length of the polymer (longer alkyl sidechains giving slower release rates) and to the concentration of monomer used to form the nanocapsules [El Samaligly et al., 1986]. Additionally, the release of low molecular weight drugs was found to depend on the partition coefficient between the internal and external media. Indeed, Ammoury et al., 1990 showed that release of indomethacin was accelerated by the presence of albumin in the external medium, because this drug can bind to albumin.

When higher molecular weight drugs are involved, diffusion mechanisms through the polymer become limited even if the drugs are soluble in the external medium. As a consequence, the release rates are generally slower and depend more to the degradation of the drug carrier [Lambert et al., 2000a, Pitaksuteepong et al., 2002, Hillaireau et al. 2007]. Interestingly, this property was used to retain highly water soluble low molecular weight compounds such as nucleoside triphosphates in nanocapsules. Indeed, the co-encapsulation of a polycation, such as poly(ethylenimine) or chitosan, in the nanocapsules promoted high rates of drug encapsulation thanks to the formation of ion pairs between the polycation and the nucleosides. This drug scavenging method also slowed down the release properties of the nanocapsules [Hillaireau et al. 2006a]. Recently, considering nanospheres, a method was suggested to modify the properties of the inside of nanospheres by incorporation of moderate percentages of methylmethacrylate (5-10\%) in the alkylcyanoacrylate monomer during the preparation of the nanospheres by emulsion polymerization [Bravo Osuna et al., 2007a]. This approach can be very useful to modulate the drug encapsulation capacity and drug releasing properties of the nanospheres. It could be used to tune nanosphere properties according to desire specifications.

\section{CONDITIONING POLY(ALKYLCYANOACRYLATE) NANOPARTICLE PREPARATIONS FOR IN VIVO DELIVERY OF DRUGS.}

Before being used in vivo, the nanoparticles need to be purified to remove free drug when encapsulation rate is rather low and traces of organic solvent when preparations are performed by either interfacial polymerization, nanoprecipitation, or emulsification-solvent evaporation (Figure 1). In general, organic solvent can be removed from preparations by lowpressure rotary evaporation. Water-containing nanocapsules which are dispersed in an oil continuous phase can be transferred in a water continuous phase by centrifugation over a cushion of an aqueous solution of surfactant [Lambert et al., 2000a]. To remove non encapsulated drug, nanoparticles can be separated from the continuous phase and any non encapsulated substance by centrifugation. Nanospheres are collected in the pellets while oilcontaining nanocapsules are recovered either in the pellet or as a floating layer depending on the density of the oil entrapped in the cavity of the nanocapsules [Gallardo et al., 1993, Vauthier et al., 1999]. If the nanocapsule density is very close to that of water, density gradient centrifugation will be necessary [Vauthier et al., 1999]. Gel filtration, dialysis and diafiltration can also be used to purify nanoparticles. A tangential filtration system is recommanded because the polymer nanoparticles tend to clog membranes and that this method can be easily applied in large scale production. Finally, as a general rule, all possible polymer aggregates must be removed from the nanoparticle suspensions before it will be injected. Thus, although PACA nanoparticles are generally rather free from polymer aggregates, they are filtrated through sintered glass or filter membranes for safety reasons prior administration. 
Administration of nanoparticle suspensions by parenteral routes will also require that the pharmaceutical preparation will be sterile. This is a challenge considering such kind of drug formulations which requires so far that all the preparation process will be done under aseptic conditions [Verdun et al., 1986, Fouarge et al., 1989, Sommerfeld, 1998]. Indeed, their size and the high particle densities obtain mean that sterilizing filtration is usually not a possible method to apply. Thermal sterilization can accelerate polymer degradation, as well as being potentially deleterious for the encapsulated substance. Sterilization by gases or ionizing radiation is not suitable either. Recently, a new method of sterilization was investigated on $\mathrm{P}$ (HDCA-Co-PEGCA) nanospheres and nanocapsules using high hydrostatic pressure. The nanoparticles appeared to resist the high pressure used in this method and the process allowed the successful inactivation of vegetative forms of bacteria, yeast and fungi. However, spores which are baroresistant were not totally destroyed during the treatment [Brigger et al., 2003]. Further exploration of the method is needed to improve the performance of the process and find protocols that are able to inactivate spores. This is worth to be done because this method represents a very interesting alternative to the other sterilization methods used so far and could avoid the use the aseptic procedure which requires special laboratory facilities and increase cost of production.

PACA nanoparticles are generally stored in good conditions as suspensions. The bacteriostatic and fungicidal activity of these nanoparticles is probably a favorable factor contributing to the high stability of the dispersions [Forestier et al., 1992, Fouarge et al., 1989]. However, lyophilization is generally preferred as conditioning storage method for pharmaceuticals. The most common problems encountered with lyophilized nanoparticle formulations are due to the difficulty of the redispersion after freeze drying which often led to aggregates instead of dispersions showing same characteristics than the parent dispersion [Abdelwalded et al. 2006]. It is also very delicate to freeze dry nanocapsules because of their thin polymer wall which may be broken during the freezing step. Both of these types of problems can be solved by adding cryoprotective agents in the parent dispersion prior to lyophilization and to apply a thermal treatment during the lyophilization cycle [Fouarge et al., 1989, Nemati et al. 1992, Layre et al. 2006a]. Redispersion properties are also intimately link to the stabilization of the nanoparticles. For instance, nanoparticles prepared with $2 \%$ pluronic as stabilizing agent could be freeze-dried without any modification of their size avoiding the use of cryoprotecting agents [Seijo et al. 1990]. Subtle modifications of the nanoparticle surface properties affect dramatically the redispersion properties of lyophilised nanoparticles. Indeed, it was recently shown that redispersion of freeze dried PACA nanospheres depended on the mechanism of polymerization used for their synthesis. This defines the steric organization of the stabilizing polysaccharide chains exposed on the nanoparticle surface. Thus, lyophilized PACA nanospheres synthesized by redox radical emulsion polymerization can be redispersed without modification of the size characteristics while the nanospheres synthesized by the anionic emulsion polymerization remained aggregated and are very difficult to redisperse if no cryoprotecting agent is added to the suspension prior lyophilization [Nemati et al. 1992, Bertholon et al., 2006d].

From a practical point of view, it is important to consider if innovative delivery systems, which are necessarily developed at the scale of the laboratory, can be successfully transposed to industry, and produced at a large scale. It is noteworthy that the startup company BioAlliance Pharma (Paris, France) is now producing PACA nanoparticles for clinical uses in phase III trials [Dufour-Lamartinie et al., 2006]. This implies that all the different pharmaceutical characteristics of the colloidal systems are now perfectly controlled. 


\section{DESIGN OF POLY(ALKYLCYANOACRYLATE) NANOPARTICLES FOR THE CONTROLLED DELIVERY OF DRUGS BY THE ORAL ROUTE.}

The oral route is the most convenient route for the administration of drugs. It allows high compliance with patients, safety and provides an easy way to deliver drugs at low cost. Although the oral route is widely used for local or systemic treatments with a wide variety of drugs, there are many compounds which cannot be administered efficiently by this route with conventional pharmaceutical formulations because their bioavailability is strongly hampered by various phenomena. Due to their small size, nanoparticle formulations behave very differently from conventional dosage forms after oral administration. They can protect drugs against degradation. They can diffuse and interact with the mucus, thus slowing down their own transit and therefore, the one of the associated drug enhancing the ability for the drug to be absorbed. They can be translocated across the epithelial membrane serving as transporters of the drug. Finally, nanoparticles can represent, in some situation, a mean of increasing dissolution rates, which is of interest when the dissolution process in the fluids is a limiting step to absorption (class II products of the biopharmaceutical classification).

The oral route is extremely challenging for the administration of peptides and proteins because these hydrosoluble macromolecules are unable to overcome mucosal barriers by themselves and are highly degraded before they can reach the blood stream. However, much attention has been paid on oral delivery of peptides because some of them are used in treatments of metabolic disease like diabetes and osteoporosis which concerns millions of patients requiring chronic treatments. Obviously, an efficient oral formulation would be a real benefit for these patients. Oil containing and water containing PACA nanocapsules were designed for oral administration of a couple of therapeutic peptides: calcitonin [Vranckx et al. 1996, Lowe and Temple, 1994], cyclosporin A [Bonduelle et al., 1992], octreotide [Damgé et al. 1997], somatostatin and insulin [Damgé et al. 1988, 1997, Watnasirichaikul et al., 2002b]. For instance, the oil-containing poly(isobutylcyanoacrylates) nanocapsules designed for the oral administration of insulin were shown to reduce the glycaemia in diabetic rats already 15 years ago [Damgé et al., 1988]. The activity profile was rather unexpected because hypoglycaemia appeared 2 days after a single dose administration and was maintained for up to 15 days depending on the insulin dose, although the amplitude of the pharmacological effect (minimal glycaemia) did not depend on the insulin dose. Other nanocapsules with an oily core but containing calcitonin behaved similarly to the insulin-loaded nanocapsules [Damgé et al., 1997, Lowe and Temple, 1994]. By another way, insulin-loaded water-containing nanocapsules dispersed in a biocompatible microemulsion were also reported to facilitate the oral absorption of the encapsulated peptide. A reduction of the blood glucose level was observed in diabetic rats after intragastric administration of the insulin-loaded poly(butylcyanoacrylate) nanocapsules [Watnasirichaikul et al., 2002b]. In another example, the absolute bioavailability of calcitonin was estimated to be $45 \%$ when it was administered orally in rats as a formulation of water-containing nanocapsules [Vranckx et al., 1997]. In general, the encapsulation of peptides in PACA nanocapsules provides an efficient protection of the peptide against proteolytic degradation. In addition, the formulations improved and prolonged the therapeutic effect of the peptide after oral administration to animals.

Apart from peptides and proteins, the bioavailability of other drugs was increased after association with poly(alkylcyanocrylate) nanospheres. For instance, the absolute bioavailability of vincamine adsorbed on PIHCA nanoparticles in rabbits reached values of $40 \%$ while the absolute bioavailability of a solution of vincamine in water was only $25 \%$ [Maincent et al., 1986]. Bioavailability increases were also observed with mitoxantrone, a lipophilic drug 
incorporated in poly(butylcyanoacrylate) nanospheres [Beck et al., 1993]. In some situations, pharmacokinetic profiles can be favourably improved. This was the case with darodipine, a calcium flux inhibitor which causes strong vasodilatation with a short half-life (2-4 h) [Hubert et al., 1991].

Many factors can explain the increased bioavailability of drugs given by the oral route when they are administered as nanoparticle formulations. PACA nanocapsules are stable in the gastric media preserving drugs, including peptide, from degradation protected because they are inside the nanocapsules. In the intestine, the nanocapsules can be degraded by pancreatic esterases releasing most of the encapsulated peptide over a period of $30 \mathrm{~min}$. However, during the same period of time, the PACA nanocapsules can deposit on the mucosa along the intestinal tract where they can be absorbed as evidenced by fluorescent and electron microscopy [Damgé et al., 2000, Aboubakar et al., 2000, Pinto-Alphandary et al., 2003, Cournarie et al., 2002]. Obviously, because of their small size, nanoparticles of diameter below $150 \mathrm{~nm}$ can be translocated across the intestinal epithelium improving the bioavailability of peptides and other drug molecules when administered by the oral route. Whatever, the importance of the uptake mechanism of intact nanoparticles remains quite controversial (Florence 2005).

Another interesting issue of the PACA nanoparticle technologies is given by the possibility to target the gut associated lymphoid tissues (GALT), including Peyer's patches. This gives different opportunities, delivering molecules specifically to specialized cells of the GALT. For instance, antigens can be delivered directly to antigen presenting cells to develop mucosal vaccines [O'Hagan 1989, Fattal et al., 1997, Shakwek et al., 2004]. Indeed, there are evidences that PACA nanoparticles can be taken up by M-cells being then translocated and transferred to dendritic cells at the level of Peyer's patches [Michel et al., 1991]. It was suggested that the improved uptake of the nanoparticles by the M-cells was favoured by the hydrophobic and anionic nature of the PACA nanospheres obtained with dextran by anionic-emulsion polymerization or of the oil-containing nanocapsules obtained by interfacial polymerization. Another example is given with AZT, a water soluble nucleosidic analog used in the treatment of HIV infections with a limited biological half-life of 1 hour. This drug is easily absorbed through the gut and does not accumulate in the intestinal tissues where immunocompetent cells of the GALT represent an important reservoir for HIV. Following oral administration experiments in rats, it was shown that large amounts of AZT could be targeted in the intestinal mucosal tissues when a particulate suspension of poly(isohexylcyanoacrylate) nanospheres was administered compared to a water solution of AZT. The nanoparticles accumulated in the mucus layer due to a bioadhesion phenomenon [Lobenberg et al., 1997, Ponchel and Irache, 1998] and in Peyer's patches after capture. The intestinal concentration in AZT obtained in the gut was much higher than the IC50\% concentration of the drug [Dembri et al., 2001] and could never be obtained with the AZT solution.

Improvements of drug bioavailability can not be only explained by the single effect of the translocation of nanoparticles across the epithelium since it seems that this mechanism is rather marginal [Florence 2004]. Another contribution comes from a prolonged period of contact of the drug delivery system with the mucosa. Indeed, it is likely that bioadhesive interactions are sufficient to modify absorption patterns of many drugs. Bioadhesion of nanoparticles to the intestine was clearly highlighted after peroral administration of radiolabelled poly(isobutylcyanoacrylate) nanospheres to mice in which whole body autoradiography revealed that the particles were localized in the stomach $30 \mathrm{~min}$ after administration but, that a large amount of radioactivity was still found in the intestine after 4 hours while very little radioactivity was found to be absorbed [Pimienta et al. 1992]. Therefore, 
strategies slowing down the intestinal transit of the nanoparticles were considered to improve further the performance of nanoparticulate drug carriers considered. It implies that the nanoparticles will show improved capacity to interact with mucus and to prolong contact of the drug with its absorption sites thus enhancing its bioavailability. Concerning adhesion of nanoparticles on mucosa, after dilution in the gastrointestinal fluids, the general mechanism depends basically on the kinetics of the particles to diffuse into the suspension medium and on the ability of the particles to interact with mucin glycoproteins or other mucus components for being immobilized within the mucus layer, and finally for a fraction of them to be possibly captured by mucosal cells (Durrer et al., 1994a; 1994b; Ponchel and Irache, 1998). Different parameters can be adjusted tuning PACA nanoparticle characteristics to modify interactions with mucus hence optimizing the adsorption pattern of the drug associated with the nanoparticles. In this aim, size and surface properties of the nanoparticles are accounted among the major characteristics influencing the mechanisms involved in the bioadhesion phenomena [Ponchel Irache 1998, Florence 2004, 2005]. A direct dependence of the size of PACA nanoparticles was found on their bioadhesive properties [Bertholon et al., 2006c, BravoOsuna 2007b]. A high bioadhesive capacity was observed for the nanoparticles of small hydrodynamic diameter $(200-300 \mathrm{~nm})$. This can be explained by the fact that small particles are diffusing faster in the mucus hydrogel layer than larger particles [Ponchel and Irache, 1998, Norris et al., 1998]. A possible strategy for further enhancing the interactions between nanoparticles and mucosa consists in modifying the surface composition of the nanoparticles. Indeed, more or less specific interactions of the nanoparticles with mucus as well as the intensity of the interactions can be promoted according to the choice of material composing the nanoparticle surface (Durrer et al., 1994a, Bertholon et al., 2006c). Interactions based on hydrogen bonding, van der Waals forces or electrostatic interactions are increased with hydrophilic polymers forming hydrogels at the nanoparticle surface and having the ability to adhere on wet mucosal surfaces. For instance, this can be achieved by coating PACA nanoparticle surface with chitosan, a cationic polysaccharide [Yang et al., 2000, Bertholon et al., 2006c]. As demonstrated by Bertholon et al., 2006c, such interactions are sensitive to the conformation of the chains standing at the nanoparticle surface. This was explained by the fact that mobile/flexible polymer chains of the nanoparticle surface and glycoproteins of the mucus can interpenetrate and entangle together during the adhesion phenomena. Although this effect is subtle, it has been shown that the conformation of polysaccharide grafted at the nanoparticle surface was important for modulating interactions. For example, a brush conformation is obtained when using the redox radical emulsion polymerisation, which appeared more favorable to promote interactions of nanoparticles with mucus glycoproteins compared with the more compact loop conformation of polysaccharide chains obtained by preparation of the nanoparticles by anionic emulsion polymerization (Bertholon et al., 2006c). Specific interactions of PACA nanoparticles with mucus glycoproteins can be promoted by grafting either specific ligands, such as lectins or chitosan derivatives including free reduced thiol groups in their structures [Yang et al. 2000, Bertholon et al. 2006c, Bravo Osuna et al., 2007b]. Lectins are specific for sugar moieties bear by the mucus glycoproteins and can be used to develop privileged interactions of the nanoparticles with defined zones of the intestine corresponding to the best absorption sites for the carried drug [Irache et al., 1996]. Presence of high amounts of free thiol groups on the nanoparticle surface importantly increased the bioadhesion of the nanoparticles because covalent bonds with cysteine residues of glycoproteins of the mucus can be formed. However, the presence of a cross-linked structure in the gel layer formed by the polysaccharide on the nanoparticle surface, due to the formation of intra- and inter-chain disulfide bonds, can reduce the interaction with mucins [Bravo-Osuna et al. 2007b]. Whatever, the intensity of this phenomenom can be adjusted varying the density of the "reactive" thiol groups at the nanoparticle surface modifying the 
percentage of chitosan, as well as the amount of 4-thiol butylamidine (TBA) used during the nanoparticle preparation.

Beside optimized bioadhesive properties, components of the nanoparticles can have an active role promoting the absorption of the drug associated with the nanoparticles. For instance, it was suggested that cyclodextrin used in the formulation of saquinavir-loaded poly(isobutylcyanoacrylate) and poly(isohexylcyanoacrylate) nanospheres plays a possible inhibitory effect on the Pgp efflux pump which opposes the absorption of the antivirial compound. Thus, the improved rate of diffusion of saquinavir through Caco-2 cell monolayers observed when it was formulated as nanospheres was attributed to the combination of a high dispersion of saquinavir in the particles and the inhibition of drug efflux pumps [Boudad et al., 2002]. In another work, it was shown that the paracellular permeation of the intestinal tissue could be modulated by the opening of the tight junctions in a controlled manner depending on the nature of the nanoparticle coating material. This can be achieved with thiol groups added at the surface of the poly(isobutylcyanoacrylate) nanospheres by coating them with thiolated chitosan. It has been suggested that this effect could be corelated to chelation of divalent ions, such as calcium [Bravo-Osuna et al., 2007c] by thiolated chitosan chains. Interestingly, the permeation effect is related to the bioadhesion of nanoparticles, which is a prerequisite for observing an increase in paracellular permeation, which suggests that thiolated chitosan exert a much-localized effect, in the vicinity of the particle and close to the epithelium. However, there is a balance between between adhesion and interactions with tight junctions likely because the thiolated chitosan is responsible simultaneously for these effects. Therefore, depending on the application, an optimum must be found to optimize the permeability enhancing properties of the nanoparticles. Indeed, at the level of the endothelial cells, it was suggested that the combination of both the remaining cationic charged of chitosan on the particle surface and the presence of thiol groups could promote the opening of the tight junctions [Bravo-Osuna et al., 2007d].

As can be seen, different mechanisms can be responsible for the promotion of drug absorption by the mean of PACA nanoparticles, depending on their surface properties, as well as their functionalities. Although further work is still required to clarify all the mechanisms by which nanoparticles can promote drug absorption by the oral route [Florence, 2004, 2005, PintoAlphandary et al. 2003], it should be kept in mind that drug release profiles from the nanoparticles should match the adhesion period for obtaining an optimal effect. Interestingly, drug release from PACA nanoparticles can be adjusted in such a way that it is completed on a period of a few hours, corresponding to the bioadhesion duration [Montisci et al., 2001].

\section{DESIGN OF POLY(ALKYLCYANOACRYLATE) NANOPARTICLES FOR THE CONTROLLED DELIVERY OF DRUGS BY THE INTRAVENOUS ROUTE}

Despite the fact that the oral route is the most convenient for the administration of drugs, a lot of drugs cannot be administered by this route. This includes many of the drugs used in the treatment of major health threats like severe infections, cancers, auto-immune diseases, and neurodegenerative diseases. Such molecules are then directly injected in the blood. However, once in the blood, the drug distributes throughout the body as a function of its own physicochemical properties. A pharmacologically active concentration in the diseased tissue is often reached only at the expense of massive contamination of the rest of the body. This is further complicated when efficacies of conventional treatments are hampered by the occurrence of drug resistance mechanisms or when the drug is degraded in the body. For 
cytostatic compounds such as anticancer drugs and anti-infectious agents, this poor specificity of the biodistribution raises a crucial toxicological problem which represents a serious obstacle to an effective and safe therapy. The rationale behind the association of a drug with colloidal carriers is that these systems can be exploited to carry the drug in the blood in a controlled manner from the site of injection to the therapeutic target. The target can be a tissue, a specific cell and the subcellular compartment of a diseased cell. This targeting implies that the drug delivery system is properly designed to carry the drug down to its target site going across the numerous physiological barriers which separates the administration site and the diseased tissue [Gref et al., 2000, Basu and Lala, 2004, Moghimi, 2005, Kommareddy et al., 2005, Nobbs et al., 2004, 2006 Vauthier et al., 2003b, Vauthier and Couvreur, 2006, 2007, Vonabourg et al., 2006]. This represents the most challenging goal in drug targeting.

As a general rule to start with, the injected particles should be individually submicronic and should not agglomerate to be able to circulate. Too large particles and agglomerates accumulate into lung capillaries which act as sieves in humans. Diffusion of particles through different biological barriers is facilitated by small size. Particles with a diameter below $100 \mathrm{~nm}$ are generally more slowly cleared from the vascular compartment by macrophages of the host defence system, i.e., the Mononuclear Phagocytes System (MPS). It was claimed that they are able to circulate for several hours in the blood stream [Moghimi, 2005]. Small size of particles also promotes their diffusion through fenestration of the altered blood vessels found in certain diseased tissues. Thus, the nanoparticles can distribute in these tissues thanks the Enhanced Permeation Retention (EPR) effect. PACA nanospheres of diameter below $100 \mathrm{~nm}$ can be prepared by anionic emulsion polymerization using a concentration in pluronic lower than $1 \%$. Other PACA nanospheres with diameters around $80 \mathrm{~nm}$ were obtained by redox radical polymerization by using the initiating system heparin/cerium IV.

In addition to size criteria, surface properties of nanoparticles seem to be key factors controlling the in vivo fate of nanoparticles after intravenous injections because they greatly influence interactions taking place between blood proteins and nanoparticles. One of the advantages of PACA nanoparticles is that they can be prepared by different methods. Additionally, most of these methods are versatile making possible confering the nanoparticles with a wide range of surface properties [Perracchia et al., 1997b, Bertholon et al., 2006b, c]. Intensive research has been carried out on this topic leading to the synthesis of numbers of PACA nanoparticles that potentially allows different levels of drug targeting after in vivo administration by intravenous injection.

A measure of the complement activation induced in human serum by the nanoparticles can be performed in vitro to predict whether the nanoparticles will be taken up by macrophages of the host defence mechanisms or whether they will have a chance to remain in the bloodstream [Vonabourg et al., 2006, Passirani et al., 1998]. For instance, dextran coated PACA nanoparticles obtained by anionic emulsion polymerization are strong activators of the complement systems and are rapidly taken up by macrophages of the MPS. It can be taken advantage of this uptake to target drugs in the liver and in the spleen. Such nanoparticles loaded with doxorubicin were suggested to treat liver metastasis while the cardiac toxicity of the drug was clearly minimized [Couvreur et al., 1980, 1982, Verdun et al. 1990, Chiannilkulchai et al., 1989]. Moreover, as these nanoparticles were also active against multidrug resistant cancer cells, they are now developed in clinical trials as drug delivery systems for doxorubicin to treat hepato-cellular carcinoma in human (Kattan et al. 1992, Colin de Verdiere et al., 1994, 1997, Barraud et al., 2005, Dufour-Lamartinie et al., 2006). Another interesting era of applications concerns the delivery of anti-infectious agents into infected macrophages. A series of spectacular results were reported. The activity of primaquine against 
intracellular Leishmania donovanii increased by 21-fold after association with poly(isohexylcyanoacrylate) nanospheres when compared to the activity of the free drug [Gaspar et al., 1992]. The toxicity of dehydroemetine, another drug candidate for the treatment of visceral leishmaniosis, was reduced after linkage with the same kinds of nanospheres [Fouarge et al., 1989]. In another example, it was reported that poly(isohexylcyanoacrylate) nanospheres loaded with ampicillin were more efficient to cure infected mice than free ampicillin than ampicillin-loaded liposomes [Fattal et al., 1991]. The efficacy of the antibiotic treatment was increased by 120 -folds after association with the nanospheres compared to treatments with the free drug in the experimental acute infection of mice by Salmonella typhimurium [Fattal et al., 1989, 1993].

The main challenge of the last decade was to design nanoparticles escaping the efficient recognition and uptake of such drug delivery systems by macrophages hence remaining in the blood stream. In this aim, PACA nanoparticles coated with PEG were developed and a new method for the preparation of polysaccharide-coated nanoparticles based on the redox radical emulsion polymerization was proposed [Perracchia et al., 1997b, Chauvierre et al., 2003b, Bertholon et al., 2006b]. The PEG- coated nanoparticles obtained from the copolymer P(HDCACo-PEGCA) were found to escape the capture by macrophages and remained in the blood for an extended period of time. Because of their long circulating properties, these nanoparticles were shown to display a very interesting increased distribution towards the brain [Calvo et al. 2001a,b, 2002, Brigger et al., 2002b]. They were found to improve the delivery of drugs in non inflamed brain tissues [Calvo et al., 2001b]. This provides a step over a very challenging issue due to the high restriction in drug transport across the very efficient blood brain barrier (BBB) representing a major limitation for treatments of diseases of the central nervous system. Results of a recent study on these nanoparticles have shown that the nanoparticle surface have a high affinity for serum apolipoprotein E (Apo-E) allowing them to be endocytosed by the brain endothelial cells using the low density lipoprotein receptor (LDLR)-mediated pathway [Kim et al., 2007a,b].

Although other nanoparticles were developed so far, they were not yet all tested for their in vivo biodistribution. However, from the in vitro assay investigating their capacity to activate the complement system, it can be expected that there are other possible candidates escaping the massive capture by macrophages of the MPS [Vonabourg et al., 2006, Passirani et al., 1998]. Among those systems, nanoparticles coated with PEG but obtained by anionic polymerization showed a reduced capacity of activate the complement system. Unexpectedly, the complement activation patterns given by nanoparticles obtained with PEG and with MePEG were not equivalent. This can be explained by a very subtle difference between the two types of nanoparticles. Indeed, in the first case, PEG chains can arrange as long loops at the nanoparticle surface having two anchorage points in the nanoparticle core, one at each end of the PEG chain (Figure 2). In the second case, the PEG chains are forming a brush of hairs at the nanoparticle surface being anchorage at the nanoparticle core by one chain end [Peracchia et al., 1997b] (Figure 2). Dextran-coated nanoparticles obtained by the redox radical emulsion polymerization were found to have low complement activation capacity when they were prepared with dextran of molecular weight higher than $10000 \mathrm{~g} / \mathrm{mol}$ [Bertholon et al., 2006b]. This was totally unexpected because the corresponding nanoparticles obtained by anionic-emulsion polymerization showed strong complement activating properties [Labarre et al., 2005, Bertholon et al., 2006b]. Same kinds of results were obtained with nanoparticles coated with other polysaccharides including chitosan, heparin, and dextran sulphate. This can be explained by the difference of the polymer structure synthesized by the two methods of polymerization implying different spatial arrangements of the polysaccharide chains standing at the nanoparticle surface to insure the stability of the colloids [Bertholon et al., 2006a, d] 
(Figure 2). In the same line, each nanoparticle showed a single protein adsorption pattern which depended in the nature of the polysaccharide coating, the molecular weight of the polysaccharide and the method of preparation of the PACA nanospheres imposing the conformation of the polysaccharide chains at the nanoparticle surface [Labarre et al., 2005]. Thus, these findings further emphasised the importance of the nanoparticle surface properties to control the in vivo fate of the drug delivery devices. Indeed, they clearly highlighted that the conformation of the macromolecules grafted on the surface of PACA nanoparticles is another parameter which influences the interactions of the nanoparticles with blood components hence which may influence their biodistribution [Labarre et al., 2005, Bertholon et al., 2006b]. A lot of work remains to be done to fully understand the effect of the properties of PACA nanoparticle surface obtained with different coating materials and by the different methods to better understand their interactions with serum proteins and in turn the consequences on their biodistribution. However, from the present data, several general rules can be suggested depending on the coating material (none, PEG, polysaccharide) and conformation (brush, loops and trains) to design PACA nanoparticles delivering drugs either to macrophages of the MPS (uncoated nanoparticles, polysaccharide-coated nanoparticles in loops and trains conformation) or outside of the MPS area (PEG-coated nanoparticles, polysaccharide-coated nanoparticles in brush conformation) [Nobs et al., 2004, Bertholon et al., 2006b, Vonabourg et al., 2006].

From the point of view of drug targeting, the nanoparticles remaining in the blood are simple and passive drug delivery systems with no specific targeting properties unless their adsorbed specific serum proteins. Generally, they are exploiting the differences in the microvascular permeability between healthy and altered tissues and their long circulating properties to concentrate in inflamed and tumor tissues. To achieve specific targeting, a higher degree of sophistication of the drug delivery system is required. This can be achieved by the grafting of a specific targeting ligand on the nanoparticle surface thanks to the presence of chemical groups that can be activated [Nobs et al., 2004, 2006]. For instance, amino groups were introduced at the surface of $\mathrm{P}(\mathrm{HDCA}-\mathrm{Co}-\mathrm{PEGCA})$ nanoparticles using mono-aminoPEG during the synthesis of the copolymer forming the nanoparticles. These amino groups were then used to graft folate residues at the nanoparticle surface resulting in a very specific capacity of the nanoparticles to interact only with cells expressing the folate receptor [Stella et al., 2000]. Interestingly, surface plasmon resonance revealed that folate grafted to PEG-coated PACA nanospheres had a 10fold higher apparent affinity for the folate-binding protein (FBP) than free folate did. The particles represent a multivalent form of the ligand folic acid, and folate receptors are often disposed in clusters. As a result, conjugated nanospheres could display a multivalent and hence stronger interaction with the surface of the malignant cells [Stella et al., 2000]. It can be expected that similar kinds of grafting chemistry can also be applied on polysaccharide-coated nanoparticles. In this sense, the successful grafting of 4-amino TEMPO achieved for physicochemical characterization purpose of the nanoparticle surface provided a relevant proof of feasibility to apply techniques of surface modifications based on chemistry on the polysaccharide coated nanoparticles [Bertholon et al., 2006d]. So far, only a few ligandreceptor couples having interest for specific targeting of drugs to cancer cells were clearly identified. Future works from biology will provide with new examples. It can also be expected that new developments will follow strategies taken up from Mother Nature in which saccharide moieties are widely involved in signalization and recognition mechanism between cells [Gabius, 2004, Vauthier et al., 2007]. In this area, the versatile methods of preparation of polysaccharide-coated nanoparticles made of PACA may represent an advantage obtaining nanoparticles with tailor made surface properties. 


\section{DESIGN OF POLY(ALKYLCYANOACRYLATE) NANOPARTICLES THE CONTROLLED DELIVERY OF DRUGS CONSIDERING LOCAL ADMINISTRATION}

The use of nanoparticles for local administration of drugs was mainly investigated for topical administration of drugs in the eye [Bu et al., 2007]. A large piece of work concerns the treatment of glaucoma and of ophthalmic inflammatory diseases. In the very first experiments performed with PACA nanoparticles, it appeared that the nanoparticles were not very well tolerated by the ocular mucosa inducing cell lysis [Zimmer et al., 1991]. Development of nanoparticles for ocular therapy were pursued considering other polymers especially poly $(\varepsilon-$ caprolactone). However, development of new formulation approaches of nanoparticles for ocular therapy encouraged some authors to reconsider PACA nanoparticles in ophthalmology. Dispersing PACA nanoparticles in a gel composed of poly(acrylic acid) or of PEG considerably improved the tolerance of these nanoparticles by reducing the primary observed toxic effect [Le Bourlais et al., 1997, Desai and Blanchard, 2000]. Another method which led to a better tolerance of PACA nanoparticles by the eye consists of preparing PACA nanoparticles coated with PEG chains [Fresta et al., 2001]. These approaches are now considered in the developments of PACA nanoparticle formulations designed as drug delivery systems for ocular therapy. For instance, PEG-coated PACA nanospheres were considered to improve the local bioavailability of tamoxifen, a non-steroidal estrogen receptor modulator, in the intraocular vitreous cavity for the treatment of autoimmune uveoretinitis (De Kozak et al. 2004). The activity of the nanospheres was tested in an experimental autoimmune uveoretinitis induced in rats. After intravitreous injections, the nanospheres were found to accumulate in the ocular tissue over a period of 3 to 9 days and the disease severity was reduced after the intraocular injection of the tamoxifen loaded PEG-coated nanospheres. This indicated that the local intraocular therapy was effective enabling the progressive local release of the drug in the eye compartment and preventing in vivo degradation and rapid metabolization of the therapeutical compounds. Moreover, the intravitreal administration of tamoxifen loaded onto PEG-coated nanospheres allowed to decrease the amount of the drug delivered to $250 \mathrm{ng} / \mathrm{eye}$ compared to $200-800 \mu \mathrm{g} / \mathrm{mice}$ usually required in treatments applied on this experimental model. From this work it clearly appeared that PEG-coated PACA nanoparticles represent a new formulation platform to achieve local delivery of drugs in treatments of ophthalmic diseases.

As suggested in another example, PACA nanospheres can be used to create a drug reservoir controlling the release of peptides after subcutaneous injection. As revealed by the autoradiographic picture, radiolabelled poly(isobutylcyanoacrylate) nanospheres accumulate in the muscular tissue after injection. Then, the staining of the autoradiography decreased progressively with time suggesting that the nanospheres are progressively biodegraded enabling the release of the entrapped growth releasing factor [Gauthier et al., 1992, Grangier et al., 1991]. After association with the nanospheres, the bioavailability of the peptide was improved indicating that the peptide could be protected from massive enzymatic degradation whereas it was very quickly metabolized at the injection site when it was administered as the free drug.

Finally, local administration of PACA nanoparticles includes a number of works in which the drug formulated as nanoparticles was administered intra-tumorally. In clinics, this method of administration can only be applied treating cancer in which a rather accessible solid tumor was identified. However, such administration method was mainly applied in research to investigate 
antitumor activity of nanoparticulate formulations of antisense oligonucleotides and of small interfering RNA (siRNA) [Schwab et al., 1994, Lambert et al., 2000b, Maksimenko et al., 2003, 2005 , Toub et al., 2006a, c]. The merit of this route of administration is that it allows investigating the success of a drug delivery method at a local level hence avoiding adverse uncontrolled phenomena that may occur when the formulations are administered at a more general level (i.e. intravenous route). The experiments performed with nanoparticle formulations of oligonucleotides have demonstrated for the first time that a specific reduction of tumor growth in mice can be induced in vivo by targeting specific sequences of either antisense oligonucleotides or siRNA associated with an appropriate PACA nanoparticle thanks to a specific antisense effect. For instance, siRNA-loaded PIBCA nanocapsules were found to trigger a dose dependant inhibition of tumor growth on a mice xenografted EWS-Fli1expressing tumor. The activity which is specific to the siRNA targeted against the EWS-Fli-1 oncogene can be explained by an intracellular penetration of the siRNA which was improved using nanocapsules and by a cytoplasmic localization of the targeting sequence [Toub et al., 2006a]. Results from these works are suggested that nanocapsules and nanospheres can be considered as promising systems for in vivo delivery of oligonucleotides improving both their stability and their intracellular penetration.

\section{CONCLUSION.}

PACA are highly interesting polymers considered as building material for various nanoparticle structures suitable to control the delivery of drugs in vivo including considering targeting strategies. Two major characteristics can be identified to make them appealing candidates. Firstly, compared to many other degradable polymers, their remarkable in vitro stability and their rapid in vivo degradation triggered by esterases present many advantages. Those include the possibility to store the nanoparticle formulation and then to control the drug release occurring in vivo on reasonable durations which are compatible with many pharmaceutical applications. Secondly, the properties of PACA nanoparticles can be adapted to resolve many drug delivery problems thanks to the availability of various mode of preparation. Surface properties can be tuned improving the control of the interactions of the drug delivery device with living structures which are key issues to address with the aim of controlling the in vivo fate of nanoparticle drug delivery devices. Because of their versatile properties, PACA nanoparticles can cargo many types of drugs including the most challenging molecules such as peptides and nucleic acids. The drug can then be delivered in a controlled manner by different routes of administration. The unique characteristics of PACA nanoparticles make them very precious tools to be considered when facing drug delivery challenge. It can be expected that they will appear as part of the nanotechnology drug delivery methods that will revolutionize therapies emerging for the treatment of major health threats in humans.

\section{ACKNOWLEDGEMENTS:}

The authors wish to thank P. Couvreur for his constant support and helpful discussions and K. Broadley, from Henkel Biomedical, for his greatly appreciated support of our work in providing our group with the alkylcyanoacrylate monomers. 


\section{REFERENCES}

Abdelwahed W, Degobert G, Stainmesse S, Fessi H. 2006. Freeze-drying of nanoparticles: formulation, process and storage considerations. Adv Drug Deliv Rev. 58(15):1688-713.

Aboubakar M, Puisieux F, Couvreur P, Deyme M, Vauthier C. 1999. Study of the mechanism of insulin encapsulation in poly(isobutylcyanoacrylate) nanocapsules obtained by interfacial polymerization. J. Biomed. Mater. Res. 47: 568-576.

Aboubakar M, Couvreur P, Pinto-Alphandary H, Gouritin B, Lacour B, Farinotti R, Puisieux F, Vauthier C. 2000. Insulin-loaded nanocapsules for oral administration: in vitro and in vivo investigation. Drug Development Research 49: 109-117.

Al Khoury-Fallouh N, Roblot-Treupel L, Fessi H, Devissaguet JP, Puisieux F. 1986. Development of a new process for the manufacture of poly(isobutylcyanoacrylate) nanocapsules. Int. J. Pharm. $28: 125-136$.

Alonso MJ. 2004. Nanomedecine for overcoming biological barriers. Biomedicine and Pharmacotherapy 58: 168-172.

Altinbas N, Fehmer C, Terheiden A, Shukla A, Rehage H, Mayer C. 2006. Alkylcyanoacrylate nanocapsules prepared from mini-emulsions: a comparison with the conventional approach. J Microencapsul. 23:567-81.

Ammoury N, Fessi H, Devissaguet JP, Puisieux F, Benita S. 1990. In vitro release kinetic pattern of indomethacin from poly(D,L-lactide) nanocapsules. J Pharm Sci. 79:763-7.

Ammoury N, Fessi H, Devissaguet JP, Dubrasquet M, Benita S. 1991. Jejunal absorption, pharmacological activity, and pharmacokinetic evaluation of indomethacin-loaded poly(d,Ilactide) and poly(isobutyl-cyanoacrylate) nanocapsules in rats. Pharm Res 8: 101-105.

Aprahamian M, Michel C, Humbert W, Devissaguet JP, Damge C. 1987. Transmucosal passage of polyalkylcyanoacrylate nanocapsules as a new drug carrier in the small intestine. Biol Cell $61: 69-76$.

Arias JL, Gallardo V, Gomez-Lopera SA, Plaza RC, Delgado AV. 2001. Synthesis and characterization of poly(ethyl-2-cyanoacrylate) nanoparticles with a magnetic core. J Control Release. 77:309-321.

Arias JL, Gallardo V, Linares-Molinero F, Delgado AV. 2006. Preparation and characterization of carbonyl iron/poly(butylcyanoacrylate) core/shell nanoparticles. J Colloid Interface Sci. 299:599-607.

Arias JL, Gallardo V, Ruiz MA, Delgado AV. 2007. Ftorafur loading and controlled release from poly(ethyl-2-cyanoacrylate) and poly(butylcyanoacrylate) nanospheres. Int J Pharm. In press.

Auvillain M, Cave G, Fessi H, Devissaguet JP. 1989. Lyophilization de vecteurs Colloidaux Submicroniques. S.T.P. Pharma Sci. 5 : 738-744.

Barratt G, Puisieux F, Yu WP, Foucher C, Fessi H, Devissaguet JP. 1994. Anti-metastatic activity of MDP-L-alanyl-cholesterol incorporated into various types of nanocapsules. Int J Immunopharmacol 16 : 457-461.

Barratt G. 2004. Colloidal drug carriers: achievements and perspectives. Cell. Mol. Life Sci. 60: 21-37. 
Barraud L, Merle P, Soma E, Lefrançois L, Guerret S, Chevallier M, Dubernet C, Couvreur P, Trepo C, Vitvitski L. 2005. Increase of doxorubicin sensitivity by doxorubicin-loading into nanoparticles for hepatocellular carcinoma cells in vitro and in vivo. J. Hepatol. 42: 736-743.

Basu MK, Lala S. 2004. Macrophage specific drug delivery in experimental leishmaniasis. Curr. Mol. Med. 4: 681-689.

Beck P, Kreuter J, Reszka R, Fichtner I. 1993. Influence of polybutylcyanoacrylate nanoparticles and liposomes on the efficacy and toxicity of the anticancer drug mitoxantrone in murine tumour models. J Microencapsul. 10:101-114.

Bertholon I, Lesieur S, Labarre D, Besnard M, Vauthier C. 2006a. Characterization of dextranpoly(isobutylcyanoacrylate) copolymers obtained by redox radical and anionic emulsion polymerization. Macromolecules, 39: 3559-67.

Bertholon I, Vauthier C, Labarre D. 2006b. Complement Activation by Core-Shell Poly(isobutylcyanoacrylate)-Polysaccharide Nanoparticles: Influences of Surface Morphology, Length, and Type of Polysaccharide. Pharm Res. 23:1313-23.

Betholon I, Ponchel G, Labarre D, Couvreur P, Vauthier C. 2006c. Bioadhesive properties of poly(alkylcyanoacrylate) nanoparticles coated with polysaccharide. Journal of Nanosciences and Nanotechnology $6: 3102-09$.

Bertholon I, Hommel H, Labarre D, Vauthier C. 2006d. Properties of Polysaccharides Grafted on Nanoparticles Investigated by EPR. Langmuir. 22:5485-5490.

Bonduelle S, Foucher C, Leroux JC, Chouinard F, Cadieux C, Lenaerts V. 1992. Association of cyclosporin to isohexylcyanoacrylate nanospheres and subsequent release in human plasma in vitro. J Microencapsul 9 : 173-82.

Boudad H, Legrand P, Lebas G, Cheron M, Duchene D, Ponchel G. 2001a. Combined hydroxypropyl-beta-cyclodextrin and poly(alkylcyanoacrylate) nanoparticles intended for oral administration of saquinavir. Int J Pharm. 218:113-24.

Boudad H, Legrand P, Appel M, Coconier MH, Ponchel G. 2001b Formulation and cytotoxicity of combined cyclodextrin poly(alkylcyanoacrylate) nanoparticles on caco-2 cells monolayers intended for oral administration of saquinavir. S.T.P. Pharma Sci 11: 369-375.

Boudad H, Legrand P, Besnard M, Duchene D, Ponchel G. 2002. Drug release characteristics from combined poly(alkylcyanoacrylate) and cyclodextrin nanoparticles loaded with saquinavir.4th world meeting on Pharmaceutics, biopharmaceutics, Pharmaceutical Technology; 2002 April 8-11; Florence. Chatenay-Malabry: APGI. p 807-8.

Brasseur F, Couvreur P, Kante B, Deckers-Passau L, Roland M, Deckers C, Speiser P. 1980. Actinomycin $D$ absorbed on polymethylcyanoacrylate nanoparticles: increased efficiency against an experimental tumor. Eur J Cancer 16: 1441-1445.

Bravo-Osuna I, Vauthier C, Ponchel G. 2007a. Tuning of shell and core characteristics of chitosan decorated acrylic nanoparticles. Eur J Pharm Sci. 30:143-154.

Bravo-Osuna I, Vauthier C, Favabollini A, Palmieri GF, Ponchel G. 2007b. Mucoadhesion mechanism of chitosan and thiolated chitosan-poly(isobutyl cyanoacrylate) core-shell nanoparticles. Biomaterials 28 : 2233-2243.

Bravo-Osuna I, Millotti G, Vauthier C, Ponchel G. 2007c. In vitro evaluation of calcium binding capacity of chitosan and thiolated chitosan poly(isobutyl cyanoacrylate) core-shell nanoparticles. Int J Pharm In press 
Bravo-Osuna I., Vauthier C., Ponchel G. 2007d, Permeation enhancing behaviour of chitosanpoly(isobutylcyanoacrylate) core-shell nanoparticles. Submitted for Publication.

Brigger I, Chaminade P, Desmaele D, Peracchia MT, d'Angelo J, Gurny R, Renoir M, Couvreur P. 2000. Near infrared with principal component analysis as a novel analytical approach for nanoparticle technology. Pharm Res. 17:1124-32.

Brigger I, Chaminade P, Marsaud V, Appel M, Besnard M, Gurny R, Renoir M, Couvreur P. 2001. Tamoxifen encapsulation within polyethylene glycol-coated nanospheres. A new antiestrogen formulation. Int J Pharm 214:37-42.

Brigger I, Dubernet C, Couvreur P. 2002a. Nanoparticles in cancer therapy and diagnosis. Adv Drug deliv Rev 54: 631-651.

Brigger I, Morizet J, Aubert G, Chacun H, Terrier-Lacombe MJ, Couvreur P. 2002b. Poly(ethylene glycol)-coated hexadecylcyanoacrylate nanospheres display a combined effect for brain tumor targeting. J Pharmacol Exp Ther 303: 928-936.

Brigger I, Armand-Lefevre L, Chaminade P, Besnard M, Rigaldie $Y$, Largeteau A, Andremont A, Grislain L, Demazeau G, Couvreur P. 2003. The stenlying effect of high hydrostatic pressure on thermally and hydrolytically labile nanosized carriers. Pharm Res. 20:674-83.

Brigger I, Morizet J, Laudani L, Aubert G, Appel M, Velasco V, Terrier-Lacombe MJ, Desmaele D, d'Angelo J, Couvreur P, Vassal G. 2004. Negative preclinical results with stealth nanospheresencapsulated Doxorubicin in an orthotopic murine brain tumor model. J Control Release 100:29-40.

Bu HZ, Gukasyan HJ, Goulet L, Lou XJ, Xiang C, Koudriakova T. 2007. Ocular disposition, pharmacokinetics, efficacy and safety of nanoparticle-formulated ophthalmic drugs. Curr Drug Metab. 8:91-107.

Calvo P, Gouritin B, Brigger I, Lasmezas C, Deslys J, Williams A, Andreux JP, Dormont D, Couvreur P. 2001a. PEGylated polycyanoacrylate nanoparticles as vector for drug delivery in prion diseases. J Neurosci Methods 111: 151-155.

Calvo P, Gouritin B, Chacun H, Desmaele D, D'Angelo J, Noel JP, Georgin D, Fattal E, Andreux JP, Couvreur P. 2001b. Long-circulating PEGylated polycyanoacrylate nanoparticles as new drug carrier for brain delivery. Pharm Res 18: 1157-1166.

Calvo P, Gouritin B, Villarroya H, Eclancher F, Giannavola C, Klein C, Andreux JP, Couvreur P. 2002. Quantification and localization of PEGylated polycyanoacrylate nanoparticles in brain and spinal cord during experimental allergic encephalomyelitis in the rat. Eur J Neurosci 15 : 1317-1326.

Csaba N, Garcia-Fuentes M, Alonso MJ. 2006. The performance of nanocarriers for transmucosal drug delivery. Expert Opin Drug Deliv. 3:463-78.

Chauvierre C, Labarre D, Couvreur P, Vauthier C. 2003a. A radical emulsion polymerization of alkylcyanoacrylates initiated by the redox system dextran - cerium IV in acidic aqueous conditions. Macromolecules 36: 6018-6027.

Chauvierre C, Labarre D, Couvreur P, Vauthier C. 2003b. Novel polysaccharide-decorated poly(isobutyl cyanoacrylate) nanoparticles, Pharm Res 20 :1786-1793.

Chauvierre C, Marden MC, Vauthier C, Labarre D, Couvreur P, Leclerc L. 2004. Heparin coated poly(alkylcyanoacrylate) nanoparticles coupled to hemoglobin: a new oxygen carrier. Biomaterials 25:3081-6. 
Chauvierre C, Leclerc L, Labarre D, Appel M, Marden MC, Couvreur P, Vauthier C. 2007. Enhancing the tolerance of poly(isobutylcyanoacrylate) nanoparticles with a modular surface design. Int J Pharm. 2007 Jan 28; [Epub ahead of print]

Chavany C, Le Doan T, Couvreur P, Puisieux F, Helene C. 1992. Polyalkylcyanoacrylate nanoparticles as polymeric carriers for antisense oligonucleotides. Pharm Res 9:441-9.

Chavany C, Saison-Behmoaras T, Le Doan T, Puisieux F, Couvreur P, Helene C. 1994. Adsorption of oligonucleotides onto polyisohexylcyanoacrylate nanoparticles protects them against nucleases and increases their cellular uptake. Pharm Res 11:1370-8.

Chiannilkulchai N, Driouich Z, Benoit JP, Parodi AL, Couvreur P. 1989. Doxorubicin-loaded nanoparticles: increased efficiency in murine hepatic metastases. Sel.Cancer Ther. 5:1-11

Colin de Verdiere A, Dubernet C, Nemati F, Soma E, Appel M, Ferté J, Bernard S, Puisieux F, Couvreur $\mathrm{P}$. 1997. Reversion of multidrug resistance with polyalkylcyanoacrylate nanoparticles: towards a mechanism of action. Br J Cancer 76: 198-205.

Colin de Verdiere A, Dubernet C, Nemati F, Poupon MF, Puisieux F, Couvreur P. 1994. Uptake of doxorubicin from loaded nanoparticles in multidrug resistant leukemic murine cells», Cancer Chemother. Pharmacol. 33 : 504-508.

Conti M, Tazzari V, Baccini C, Pertici G, Serino LP, De Giorgi U. 2006. Anticancer drug delivery with nanoparticles. In Vivo 20:697-701.

Couvreur P, Kante B, Roland M, Guiot P, Baudhuin P, Speiser P. 1979. Poly(cyanoacrylate) nanoparticles as potential lysosomotropic carriers: preparation, morphological and sorptive properties. J Pharm Pharmacol 31: 331-332.

Couvreur P, Kante B, Lenaerts V, Deckers-Passau L, Roland M. 1980. Tissue distribution of antitumor drugs associated with polyalkylcyanoacrylate nanoparticules. J Pharm Sci, 69:199202.

Couvreur P, Kante B, Grislain L, Roland M, Speiser P. 1982. Toxicity of polyalkycyanoacrylate nanoparticles. II. Doxorubicin-loaded nanoparticles, J. Pharm. Sci. 71 : 790-792.

Couvreur P, Vauthier C. 2006. Nanotechnology : Intelligent design to treat complex desease. Pharm. Res. 23:1417-50

Couvreur P, Barratt G, Fattal E, Legrand P, Vauthier C. 2002. Nanocapsule technologies. Crit Rev Ther Drug Carrier Syst 19 : 99-134.

Cournarie F, Auchère D, Chevenne D, Lacour B, Seiller M, Vauthier C. 2002. Absorption and efficiency of insulin after oral administration of insulin-loaded nanocapsules in diabetic rats. Int J Pharm 242 : 325-28.

Cournarie F, Cheron M, Besnard M, Vauthier C. 2004. Evidence for restrictive parameters in formulation of insulin-loaded nanocapsules. Eur J Pharm Biopharm 57: 171-9.

Damgé C, Michael C, Aprahamian M, Couvreur P, Devissaguet JP. 1990. Nanocapsules as carriers for oral peptide delivery. J Control Release 13 : 233-239.

Damgé C, Michel C, Aprahamian M, Couvreur P. 1988. New approach for oral administration of insulin with poly-alkylcyanoacrylate Nanocapsules as drug carrier. Diabetes 37 :246-251.

Damgé C, Vonderscher J, Marbach P, Pinget M. 1997. Poly(alkylcyanoacrylate) Nanocapsules as a delivery system in the rat for octeotride, a long-acting somatostoatin analogue. J. Pharm. Pharmacol. 49 : 949-954. 
Damgé C, Aprahamiam M, Humbert W, Pinget M. 2000 lleal uptake of polyalkylcyanoacrylate nanocapsules in the rat. J Pharm Pharmacol. 52:1049-56.

de Kozak Y, Andrieux K, Villarroya H, Klein C, Thillaye-Goldenberg B, Naud MC, Garcia E, Couvreur P. 2004. Intraocular injection of tamoxifen-loaded nanoparticles : a new treatment of experimental autoimmune uveoretinitis. Europ J Immunol 34 : 3702-3712

Dembri A, Montisci MJ, Gantier JC, Chacun H, Ponchel G. 2001. Targeting of 3'-azido 3'deoxythymidine (AZT)-loaded poly(isohexylcyanoacrylate) nanospheres to the gastrointestinal mucosa and associated lymphoid tissues. Pharm Res 18 : 467-73.

Desai SD, Blanchard J. 2000. Pluronic F127-based ocular delivery systems containing biodegradable polyisobutylcyanoacrylate nanocapsules of pilocarpine. J Deliv Targeting Therap Agents 7 : 201-207.

Desgouilles S, Vauthier C, Bazile D, Vacus J, Grossiord JL, Veillard M, Couvreur P. 2003. The design of nanoparticles obtained by solvent evaporation: A comprehensive study. Langmuir 19 : 9504-9510.

Douglas SJ, Illum L, Davis SS. 1985. Particle size and size distribution of poly(butyl 2cyanoacrylate) nanoparticles. II. Influence of stabilizers. J. Colloid Interface Sci. 103: 154-163.

Duchene D, Ponchel G, Wouessidjewe D. 1999. Cyclodextrins in targeting. Application to nanoparticles. Adv Drug Deliv Rev. 36:29-40.

Dufour-Lamartinie JF, Habersetzer F, Abergel A, Merle P, Si Ahmed SN, Bonyhay L, Taieb J, Costantini D, Trepo C. 2006. Phase 1 study of intra-arterial hepatic (iah) delivery of doxorubicin-transdrug ${ }^{\circledR}$ (dt) for patients with advanced hepatocellular carcinoma (hcc). Abstract to the 12th International Symposium on Viral Hepatitis and liver disease, Paris, France July 1-5 2006. Supplement of the Journal of Clinical Virology Vol 36, Suppl. 2, July 2006

Durrer C, Irache JM, Puisieux F, Duchene D, Ponchel G. 1994a. Mucoadhesion of latexes. I. Analytical methods and kinetic studies. Pharm Res. 11:674-9.

Durrer C, Irache JM, Puisieux F, Duchene D, Ponchel G. 1994b. Mucoadhesion of latexes. II. Adsorption isotherms and desorption studies. Pharm Res. 11:680-3.

El-Samaligy MS, Rohdewald P, Mahmoud HA. 1986. Polyalkyl cyanoacrylate nanocapsules. J Pharm Pharmacol. $38: 216-8$.

El-Samaligy MS, Rojanasakul Y, Charlton JF, Weinstein GW, Lim JK. 1996. Ocular disposition of nanoencapsulated acyclovir and ganciclovir via intravitreal injection in rabbit's eye. Drug Delivery 3 : 93-97.

Fattal E, Youssef M, Couvreur P, Andremont A. 1989. Treatment of experimental salmonellosis in mice with ampicillin-bound nanoparticles. Antimicrob Agents Chemother 33 :1540-1543.

Fattal E, Rojas J, Roblot-Treupel L, Andremont A, Couvreur P. 1991. Ampicillin-loaded liposomes and nanoparticles: comparison of drug loading, drug release and in vitro antimicrobial activity. J Microencapsul 8:29-36.

Fattal E, Balland O, Alphandary H, Pecquet S, Puisieux F, Couvreur P, Andremont A. 1993. Colloidal carriers of antibiotics as an alternative approach for the treatment of intracellular infections. In Raoult D. Editor. Antimicrobial agents and intracellular pathogens. Boca Raton, Fl: CRC Press, 1993 : 63-72. 
Fattal E, Blanco-Prieto MJ, Leo E, Puisieux F, Couvreur P. 1997. Design of nanoparticles for vaccine delivery. In: Gander B, Merkle H, Corradin G, Editors. Antigen delivery systems. Hardwood academic publishers. p. 139-57.

Fattal E, Andrieux K, Barratt G, Couvreur P, Labarre D, Ponchel G, Vauthier C. 2007. In Press. Recent Advances in Polyalkylcyanoacrylate Nanoparticles for Drug Delivery. In : Domb J, Tabata Y, Ravi Kumar MNV, Farber S, Editors. Nanoparticles for Pharmaceutical Applications. New York: American Scientific Publishers. p 213-232

Florence AT. 2004. Issues in oral nanoparticle drug carrier uptake and targeting. J Drug Target $12: 65-70$.

Florence AT. 2005. Nanoparticle uptake by the oral route: fulfilling its potential? Drug disc. Today Techn 2: 75-81.

Forestier F, Gerrier P, Chaumard C, Quero AM, Couvreur P, Labarre C. 1992. Effect of nanoparticle-bound ampicillin on the survival of Listeria monocytogenes in mouse peritoneal macrophages. J Antimicrob Chemother. 30:173-9.

Fouarge $M$, Dewulf $M$, Couvreur $P$, Rolland $M$, Vranckx H. 1989. Development of dehydroemetine nanoparticles for the treatment of visceral leishmaniasis. J Microencapsul $6: 29-34$.

Fresta M, Puglisi G, Giommona G, Cavallaro G, Micali N, Furneri PM. 1995. Pefloxacin mesilateand ofloxacin-loaded polyethylcyanoacrylate nanoparticles: characterization of the colloidal drug carrier formulation. J Pharm Sci 84: 895-901.

Fresta M, Cavallaro G, Giammona G, Wehrli E, Puglisi G. 1996. Preparation and characterization of polyethyl-2-cyanoacrylate nanocapsules containing antiepileptic drugs. Biomaterials. 17:751-8.

Fresta M, Fontana G, Bucolo C, Cavallaro G, Giammona G, Puglisi G. 2001. Ocular tolerability and in vivo bioavailability of poly(ethylene glycol) (PEG)-coated polyethyl-2-cyanoacrylate nanospheres-encapsulated acyclovir. J Pharm Sci 90 : 288-297.

Gabius HJ. 2004. The sugar code in drug delivery. Adv Drug Delivery Rev 56: 421-424.

Gallardo M, Couarraze G, Denizot B, Treupel L, Couvreur P, Puisieux F. 1993. Study of the mechanism of formation of nanoparticles and nanocapsules of poly(isobutyl-2-cyanoacrylate) Int. J. Pharm. 100 : 55-64.

Gallardo MM, Roblot-Treupel L, Mahuteau J, Genin I, Couvreur P, Plat M, Puisieux F. 1989. Nanocapsules et nanospheres d'alkylcyanoacrylate. Interaction principe actif-polymère. 5ème Congrès International de Technologie Pharmaceutique ; 1989 May 30- June 1 ; Paris. ChatenayMalabry : APGI p 36-45.

Gallardo MM. 1991. Caractérisation Physico-chimique de systèmes nanoparticulaires de poly(isobutyl-2-cyanoacrylate) [dissertation]. Paris (France) : University Paris South. 233p. Available from: University of Paris South, Chatenay-Malabry France.

Ganachaud F, L. Katz J. 2005. Nanoparticles and nanocapsules created using the Ouzo effect: spontaneous emulsification as an alternative to ultrasonic and high-shear devices. Chem Phys Chem. $6: 209-216$.

Gasco M, Trotta M. 1986. Nanoparticles from microemulsions. Int J Pharm 29 : 267-268. 
Gaspar R, Preat V, Opperdoes FR, Rolland M. 1992. Macrophage activation by polymeric nanoparticles of polyalkylcyanoacrylates: activity against intracellular Leishmania donovani associated with hydrogen peroxide production. Pharm. Res. 9: 782-787.

Gautier JC, Grangier JL, Barbier A, Dupont P, Dussosoy D, Pastor G, Couvreur P. 1992. Biodegradable nanoparticles for subcutaneous adminstration of growth hormone releasing factor (hGRF). J Control Rel $3:$ 205-210.

Ghanem GE, Joubran C, Arnould R, Lejeune F, Fruhling J. 1993. Labelled polycyanoacrylate nanoparticles for human in vivo use. Appl. Radiat. Isot. 44 : 1219-1224.

Gibaud S, Rousseau C, Weingarten C, Favier R, Douay L, Andreux JP, Couvreur P. 1998. Polyalkylcyanoacrylate nanoparticles as carriers for granulocyte-colony stimulating factor (GCSF). J Control Rel 52: 131-139.

Grangier JL, Puygrenier M, Gautier JC, Couvreur P. 1991. Nanoparticles as carriers for growth hormone releasing factor. J. Control. Rel. 15 : 3-13.

Gref R, Luck M, Quellec P, Marchand M, Dellacherie E, Harnisch S, Blunk T, Muller RH. 2000. 'Stealth' corona-core nanoparticles surface modified by polyethylene glycol (PEG): influences of the corona (PEG chain length and surface density) and of the core composition on phagocytic uptake and plasma protein adsorption. Colloids Surf B Biointerfaces. 18:301-313.

Guize V, Drouin JY, Benoit J, Mahuteau J, Dumont P, Couvreur P. 1990. Vidarabine-loaded nanoparticles: a physicochemical study. Pharm Res 7: 736-741.

Harris JM. 1992. In: Harris JM, Editor Poly(ethylene glycol) chemistry. New York: Plenum press. p 3-14.

Hillaireau H, Le Doan T, Appel M, Couvreur P. 2006a Hybrid polymer nanocapsules enhance in vitro delivery of azidothymidine-triphosphate to macrophages. J Control Release. 116:346-52.

Hillaireau H, Le Doan T, Couvreur P. 2006b. Polymer-based nanoparticles for the delivery of nuclosides analogues. J. Nanosci. Nantechnol. 6: 2608-2717.

Hillaireau H, Le Doan T, Chacun H, Janin J, Couvreur P. 2007. Encapsulation of mono- and oligonucleotides into aqueous-core nanocapsules in presence of various water-soluble polymers. Int J Pharm. 331:148-52.

Huang CY, Chen CM, Lee YD. 2007. Synthesis of high loading and encapsulation efficient paclitaxel-loaded poly(n-butyl cyanoacrylate) nanoparticles via miniemulsion. Int J Pharm 2007 Feb 9; [Epub ahead of print]

Hubert B, Atkinson J, Guerret M, Hoffman M, Devissaguet JP, Maincent P. 1991. The preparation and acute antihypertensive effects of a nanocapsular form of darodipine, a dihydropyridine calcium entry blocker. Pharm Res $8: 734-8$.

Ibrahim A, Couvreur P, Rolland M, Speiser P. 1983. New magnetic drug carriers. J Pharm Pharmacol 35: 59-61.

Irache JM, Durrer C, Duchene D, Ponchel G. 1996. Bioadhesion of lectin-latex conjugates to rat intestinal mucosa. Pharm Res $13: 1716-9$.

Kattan J, Droz JP, Couvreur P, Marino JP, Boutan-Laroze A, Rougier P, Brault P, Vranckx H, Grognet JM, Morge X, Sancho-Garnier H. 1992. Phase I clinical trial and pharmacokinetic evaluation of doxorubicin carried by polyisohexylcyanoacrylate nanoparticles. Invest. New drugs $10: 191-199$. 
Kim HR, Andrieux K, Gil S, Taverna M, Chacun H, Desmaele D, Taran F, Georgin D, Couvreur P. 2007a. Translocation of poly(ethylene glycol-co-hexadecyl)cyanoacrylate nanoparticles into rat brain endothelial cells: role of apolipoproteins in receptor-mediated endocytosis. Biomacromolecules. 8:793-9.

Kim HR, Gil S, Andrieux K, Nicolas V, Appel M, Chacun H, Desmaele D, Taran F, Georgin D, Couvreur P. 2007b. Low-density lipoprotein receptor-mediated endocytosis of PEGylated nanoparticles in rat brain endothelial cells. Cell Mol Life Sci. 64:356-64.

Kommareddy S, Tiwari SB, Amiji MM. 2005. Long-circulating polymeric nanovectors for tumorselective gene delivery. Technol Cancer Res Treat. 4:615-25.

Krauel K, Davies NM, Hook S, Rades T. 2005. Using different structure types of microemulsions for the preparation of poly(alkylcyanoacrylate) nanoparticles by interfacial polymerization. J Control Release. 106:76-87.

Kreuter J. 2004. Influence of the surface properties on nanoparticle-mediated transport of drugs to the brain. J Nanosci Nanotechnol. 4:484-8.

Labarre D, Vauthier C, Chauvierre C, Petri B, Muller R, Chehimi MM. 2005. Interactions of blood proteins with poly(isobutylcyanoacrylate) nanoparticles decorated with a polysaccharidic brush. Biomaterials $26: 5075-84$.

Labib A, Lenaerts V, Chouinard F, Leroux JC, Ouellet R, Van Lier JE. 1991. Biodegradable nanospheres containing phthalocyanines and naphthalocyanines for targeted photodynamic tumor therapy. Pharm. Res. $8: 1027-1031$

Lambert G, Fattal E, Brehier A, Feger J, Couvreur P. 1998. Effect of polyisobutylcyanoacrylate nanoparticles and lipofectin loaded with oligonucleotides on cell viability and PKC alpha neosynthesis in HepG2 cells. Biochimie 80 : 969-976.

Lambert G, Fattal E, Pinto-Alphandary H, Gulik A, Couvreur P. 2000a Polyisobutylcyanoacrylate nanocapsules containing an aqueous core as a novel colloidal carrier for the delivery of oligonucleotides. Pharm. Res. 17 : 707-714.

Lambert G, Bertrand JR, Fattal E, Subra F, Pinto-Alphandary H, Malvy C, Auclair C, Couvreur P. 2000b. EWS fli-1 antisense nanocapsules inhibits ewing sarcoma-related tumor in mice. Biochem Biophys Res Commun. 279:401-6.

Layre AM, Couvreur P, Chacun H, Aymes-Chodur C, Ghermani NE, Poupaert J, Richard J, Requier D, Gref R. 2006. Busulfan loading into poly(alkyl cyanoacrylate) nanoparticles: physicochemistry and molecular modeling. J Biomed Mater Res B Appl Biomater. 79:254-62.

Layre AM, Couvreur P, Richard J, Requier D, Eddine Ghermani N, Gref R. 2006a. Freeze-drying of composite core-shell nanoparticles. Drug Dev Ind Pharm 32:839-46.

Le Bourlais CA, Chevanne F, Turlin B, Acar L, Zia H, Sado PA, Needham TE, Leverge R. 1997. Effect of cyclosporine $A$ formulations on bovine corneal absorption: ex- vivo study. J Microencapsul 14 : 457-467

Li YP, Pei YY, Zhou ZH, Zhang XY, Gu ZH, Ding J, Gao XJ, Zhu JH. 2001a. Stealth polycyanoacrylate nanoparticles as tumor necrosis factor- $\alpha$ carriers: Pharmacokinetics and anti-tumor effects. Biol. Pharm. Bull. 24 :662-665.

Li YP, Pei YY, Zhou ZH, Zhang XY, Gu ZH, Ding J, Zhou JJ, Gao XJ. 2001b. PEGylated polycyanoacrylate nanoparticles as tumor necrosis factor- $\alpha$ carrier. J. Control. Rel. $71: 287-296$ 
Limouzin C, Cavaggia A, Ganachaud F, Hemmery, P. 2003. Anionic Polymerization of n-Butyl Cyanoacrylate in Emulsion and Miniemulsion. Macromolecules 36 : 667-674.

Lobenberg R, Araujo L, Kreuter J. 1997. Body distribution of azidothymidine bound to nanoparticles after oral administration. Eur J Pharm Biopharm 44: 127-132.

Lowe PJ, Temple CS. 1994. Calcitonin and insulin in isobutylcyanoacrylate nanocapsules: protection against proteases and effect on intestinal absorption in rats. J. Pharm. Pharmacol. $46: 547-552$

Maincent P, Le Verge R, Sado P, Couvreur P, Devissaguet JP. 1986. Disposition kinetics and oral bioavailability of vincamine-loaded polyalkyl cyanoacrylate nanoparticles. J Pharm Sci 75 : 955958.

Maksimenko A, Malvy C, Lambert G, Bertrand JR, Fattal E, Maccario J, Couvreur P. 2003. Oligonucleotides targeted against a junction oncogene are made efficient by nanotechnologies. Pharm. Res. 20: 1565-1567.

Maksimenko A, Polard V, Villemeur M, Elhamess H, Couvreur P, Bertrand JR, Aboubakar M, Gottikh M, Malvy C. 2005. In vivo potentialities of EWS-Fli-1 targeted antisense oligonucleotides-nanospheres complexes. Ann N Y Acad Sci. 1058:52-61.

Marchal-Heussler L, Fessi H, Devissaguet JP, Hoffman M, Maincent P. 1992. Colloidal drug delivery systems for the eye. A comparison of the efficacy of three different polymers: polyisobutylcyanoacrylate, poly(lactic-co-glycolic acid, poly-epsilon caprolactone. S.T.P. Pharma 2 : 98-104.

Mayer C. 2005. Nanocapsules as drug delivery systems. Int J Artif Organs 28:1163-71.

Michel C, Aprahamian M, Defontaine L, Couvreur P, Damge C. 1991. The effect of site of administration in the gastrointestinal tract on the absorption of insulin from nanocapsules in diabetic rats. J Pharm Pharmacol 43:1-5.

Minko T, Pakunlu RI, Wang Y, Khandare JJ, Saad M. 2006. New generation of liposomal drugs for cancer. Anticancer Agents Med Chem. 6:537-52.

Mitra A, Nan A, Line BR, Ghandehari H. 2006. Nanocarriers for nuclear imaging and radiotherapy of cancer. Curr Pharm Des. 12(36):4729-49.

Moghimi, S.M. 2006. Recent developments in polymeric nanoparticle engineering and their applications in experimental and clinical oncology. Anticancer Agents Med Chem. 6:553-561.

Moghimi SM, Hunter AC, Murray JC. 2005. Nanomedicine: current status and future prospects. FASEB J. 19:311-330.

Montisci MJ, Dembri A, Giovannuci G, Chacun H, Duchene D, Ponchel G. 2001. Gastrointestinal transit and mucoadhesion of colloidal suspensions of Lycopersicon esculentum $L$. and Lotus tetragonolobus lectins- PLA microspheres. Pharm. Res. 18 : 829-837.

Monza da Silveira A, Ponchel G, Puisieux F, Duchene D. 1998. Combined poly(isobutylcyanoacrylate) and cyclodextrins nanoparticles for enhancing the encapsulation of lipophilic drugs. Pharm Res. 15:1051-5.

Monza da Silveira A, Duchêne D, Ponchel G. 2004. Drug release characteristics from combined poly(isobutylcyanoacrylate) and cyclodextrin nanoparticles loaded with progesterone. Polym. Sci. (série A) (Vysokomolekulyarnye soedineniya (seriya A) 46 : 1-8. 
Nemati F, Cavé GN, Couvreur P. 1992. Lyophilization of substances with low water permeability by a modification of crystallized structures during freezing. 6ème Congrès International de Technologie Pharmaceutique ; 1992 June 2-4; Paris. Chatenay-Malabry : APGI. vol. 3, p 487-493.

Nobs L, Buchegger F, Gurny R, Allemann E. 2006. Biodegradable nanoparticles for direct or two-step tumor immunotargeting. Bioconjug Chem. 17:139-145.

Nobs L, Buchegger F, Gurny R, Allemann E. 2004. Current methods for attaching targeting ligands to liposomes and nanoparticles. J Pharm Sci. 93:1980-1992.

Norris DA, Puri N, Sinko PJ. 1998. The effect of physical barriers and properties on the oral absorption of particulates. Adv Drug Deliv Rev. 34:135-154.

O'Hagan DT, Palin K, Davis SS. 1989. Poly (butyl-2-cyanoacrylate) particles as adjuvants for oral immunization. Vaccine 7: 213-216.

Olivier JC. 2005. Drug transport to brain with targeted nanoparticles. NeuroRx. 2:108-119.

Page-Clisson ME, Pinto-Alphandary H, Ourevitch M, Andremont A, Couvreur P. 1998. Development of ciprofloxacin-loaded nanoparticles: physicochemical study of the drug carrier. J Control Release 1998 56:23-32.

Passirani C, Barratt G, Devissaguet JP, Labarre D. 1998. Long-circulating nanoparticles bearing heparin or dextran covalently bound to poly(methyl methacrylate). Pharm Res. 15:1046-50.

Peracchia MT, Vauthier C, Popa M, Puisieux F, Couvreur P. 1997a. An investigation on the formation of sterically stabilized PEG-PIBCA nanoparticles by chemical grafting of PEG during the polymerization of isobutylcyanoacrylate. S.T.P. Pharma Sciences. 7: 514-521.

Peracchia MT, Vauthier C, Passirani C, Couvreur P, Labarre D. 1997b. Complement consumption by poly(ethylene glycol) in different configurations chemically coupled to polyisobutylcyanoacrylate nanoparticles. Life Sciences 61:749-761.

Peracchia MT, Desmaële D, Couvreur P, d'Angelo J. 1997c. Synthesis of novel poly(MePEG cyanoacrylate-co-alkyl cyanoacrylate) amphiphilic copolymer for nanoparticle technology. Macromolecules $30: 846-851$.

Peracchia MT, Vauthier C, Desmaël D, Gulik A, Dedieu JC, Demoy M, D'Angelo J, Couvreur P. 1998. Pegylated nanoparticles from a novel methoxypolyethyleneglycol cyanoacrylatehexadecyl cyanoacrylate amphiphilic copolymer. Pharm. Res. 15 : 550-556.

Pimienta C, Chouinard F, Labib A, Lenaerts V. 1992. Effect of various poloxamer coatings on in vitro adhesion of isohexylcyanoacrylate nanospheres to rat ileal segments under liquid flow. Int. J. Pharm. $80: 1-8$.

Pinto-Alphandary H, Aboubakar M, Jaillard D, Couvreur P, Vauthier C. 2003. Visualization of insulin-loaded nanocapsules: in vitro and in vivo studies after oral administration to rats. Pharm Res. 20 : 1071-84.

Pinto Reis C, Neufeld RJ, Ribeiro AJ, Veiga F. 2006. Nanoencapsulation II. Biomedical applications and current status of peptide and protein nanoparticulate delivery systems. Nanomedicine2:53-65.

Pitaksuteepong T, Davies NM, Tucker IG, Rades T. 2002. Factors influencing the entrapment of hydrophilic compounds in nanocapsules prepared by interfacial polymerisation of water-in-oil microemulsions. Eur J Pharm Biopharm 53:335-42. 
Ponchel G, Irache J. 1998. Specific and non-specific bioadhesive particulate systems for oral delivery to the gastrointestinal tract. Adv Drug Deliv Rev 34: 191-219.

Puglisi G, Fresta M, Giammona G, Ventura CA. 1995. Influence of the preparation conditions on poly(ethylcyanoacrylate) nanocapsule formation. Int. J. Pharm. 125 : 283-287.

Reszka R, Beck P, Fichtner I, Hentschel M, Richter J, Kreuter J. 1997. Body distribution of free, liposomal and nanoparticle-associated mitoxantrone in B16-melanoma-bearing mice. J Pharmacol Exp Ther 280:232-7.

Roy V, Perez EA. 2006. New therapies in the treatment of breast cancer. Semin Oncol 33:S3-8.

Schwab G, Chavany C, Duroux I, Goubin G, Lebeau J, Helene C, Saison-Behmoaras T. 1994. Antisense oligonucleotides adsorbed to polyalkylcyanoacrylate nanoparticles specifically inhibit mutated Ha-ras-mediated cell proliferation and tumorigenicity in nude mice. Proc Natl Acad Sci U S A 91 : 10460-10464.

Seijo B, Fattal E, Roblot-Treupel L, Couvreur P. 1990. Design of nanoparticles of less than $50 \mathrm{~nm}$ diameter: preparation, characterization and drug loading. Int J Pharm 62 : 1-7.

Shakweh M, Ponchel G, Fattal E. 2004. Particle uptake by Peyer's patches: a pathway for drug and vaccine delivery. Expert Opin Drug Deliv 1:141-63.

Sinha R, Kim GJ, Nie S, Shin DM. 2006. Nanotechnology in cancer therapeutics: bioconjugated nanoparticles for drug delivery. Mol Cancer Ther. 5:1909-17.

Sommerfeld J. 1998. Medical anthropology and infectious disease control. Trop Med Int Health. 3:993-5.

Sonvico F, Dubernet C, Colombo P, Couvreur P. 2005. Metallic colloid nanotechnology, applications in diagnosis and therapeutics. Curr Pharm Des 11:2095-105.

Stella B, Arpicco S, Peracchia MT, Desmaele D, Hoebeke J, Renoir M, D’Angelo J, Cattel L, Couvreur P. 2000. Design of folic acid-conjugated nanoparticles for drug targeting. J. Pharm. Sci. 89: 1452-1464.

Torchilin VP. 2006. Multifunctional nanocarriers. Adv Drug Deliv Rev 58 : 1532-1555.

Toub N, Bertrand JR, Tamaddon A, Elhamess H, Hillaireau H, Maksimenko A, Maccario J, Malvy C, Fattal E, Couvreur P., 2006a, Efficacy of siRNA nanocapsules targeted against the EWS-Fli1 oncogene in Ewing sarcoma. Pharm Res 23:892-900.

Toub N, Malvy C, Fattal E, Couvreur P. 2006b. Innovative nanotechnologies for the delivery of oligonucleotides and siRNA. Biomed Pharmacother 60:607-20.

Toub N, Bertrand JR, Malvy C, Fattal E, Couvreur P. 2006c. Antisense oligonucleotide nanocapsules efficiently inhibit EWS-Fli1 expression in a Ewing's sarcoma model. Oligonucleotides. 16:158-68.

Vauthier C, Schmidt C, Couvreur P. 1999. Measurement of the density of polymeric nanoparticulate drug carriers made of poly(alkylcyanoacrylate) and poly(lactic acid) derivatives. J Nanoparticle Res 1: 411-418.

Vauthier C, Couvreur P. 2002. Degradation of polycyanoacrylates. In Matsumara JP, Steinbuchel A, Editors. Handbook of Biopolymers: vol 9: Miscellanous biopolymers and biodegradation of synthetic polymers. Weinheim: Wiley-VHC. p 457-490. 
Vauthier C, Dubernet C, Fattal E, Pinto-Alphandary H, Couvreur P. 2003a. Poly(alkylcyanoacrylates) as biodegradable materials for biomedical applications. Adv Drug Deliv Rev 55:519-548.

Vauthier C, Dubernet C, Chauvierre C, Brigger I, Couvreur P. 2003b. Drug Delivery to resistant tumors : Potential of poly(alkylcyanoacrylate) nanoparticles. J Control Release 93 : 151-160.

Vauthier C, Fattal E, Labarre D. 2004. From polymer chemistry and physicochemistry to nanoparticulate drug carrier design and applications. In: Yaszemski MJ, Trantolo DJ, Lewamdrowski KU, Hasirci V, Altobelli DE, Wise DL, Editors. Biomaterial Handbook- Advanced Applications of Basic Sciences and Bioengineering. New York: Marcel Dekker, Inc. p 563-598.

Vauthier C., Couvreur P. 2007. Nanomedecines: a new approach for the treatment of severe diseases. Mini-Review of Medicinal chemistry Submitted for Publication.

Vauthier C, Bertholon I, Labarre D. 2007. Integrated development of glycobiologics: from discovery to applications in the design of nanoparticular drug delivery systems. In: Mok G. Editor. Handbook in Pharmaceutical Sciences. Weinheim : John Wiley and Son. In press.

Verdun C, Brasseur F, Vranckx H, Couvreur P, Roland M. 1990. Tissue distribution of doxorubicin associated with polyisohexylcyanoacrylate nanoparticles. Cancer Chemother Pharmacol 26:13-18.

Verdun C, Couvreur P, Vranckx H, Lenaerts V, Roland M. 1986. Development of a nanoparticle controlled release formulation for human use. J Controlled Rel 3: 205-210.

Vonarbourg A, Passirani C, Saulnier P, Benoit JP. 2006. Parameters influencing the stealthiness of colloidal drug delivery systems. Biomaterials. 27:4356-73.

Vranckx H, Demoustier M, Deleers M. 1996. A new nanocapsule formulation with hydrophilic core: application to the oral administration of salmon calcitonin in rats, Eur. J. Pharm. Biopharm. 42 : 345-347.

Vyas TK, Shah L, Amiji MM. 2006. Nanoparticulate drug carriers for delivery of HIV/AIDS therapy to viral reservoir sites. Expert Opin. Drug Deliv. $3: 613-628$.

Watnasirichaikul S, Davies NM, Rades R, Tucker IG. 2000. Preparation of biodegradable insulin nanocapsules from biocompatible microemulsions. Pharm. Res. 17: 684-689.

Watnasirichaikul S, Rades T, Tucker IG, Davies NM. 2002a. Effects of formulation variables on characteristics of poly (ethylcyanoacrylate) nanocapsules prepared from w/o microemulsions. Int J Pharm 235: 237-46.

Watnasirichaikul S, Rades T, Tucker IG, Davies NM. 2002b. In-vitro release and oral bioactivity of insulin in diabetic rats using nanocapsules dispersed in biocompatible microemulsion. J Pharm Pharmacol. 54:473-80.

Weiss CK, Ziener U, Landfester K. 2007. A Route to Nonfunctionalized and Functionalized Poly(n-butylcyanoacrylate) Nanoparticles: Preparation in Miniemulsion. Macromolecules in press

Wissing SA, Kayser O, Muller RH. 2004. Solid lipid nanoparticles for parenteral drug delivery. Adv Drug Deliv Rev. 56:1257-1272.

Wohlgemuth M, Mayer C. 2003. Pulsed field gradient NMR on polybutylcyanoacrylate nanocapsules. J Colloid Interface Sci 260: 324-31. 
Wohlgemuth M, Machtle W, Mayer C. 2000. Improved preparation and physical studies of polybutylcyanoacrylate nanocapsules. J Microencapsul 17: 437-48.

Yang SC, Ge HX, Hu Y, Jiang XQ, Yang CZ. 2000. Formation of positively charged poly(butyl cyanoacrylate) nanoparticles stabilized by chitosan. Coll Polym Sci 278 : 285-292.

Youssef M, Fattal E, Alonso MJ, Roblot-Treupel L, Sauzieres J, Tancrede C, Omnes A, Couvreur P, Andremont A. 1988. Effectiveness of nanoparticle-bound ampicillin in the treatment of Listeria monocytogenes infection in athymic nude mice. Antimicrob Agents Chemother 32:1204-7.

Zhang ZZ, He Q, Liao GT, Bai SH. 1999. Study on the anticarcinogenic effect and acute toxicity of liver-targeting mitoxantrone nanoparticles World J Gastroenter 5:511-514

Zimmer A, Kreuter J, Robinson JR. 1991. Studies on the transport pathway of PBCA nanoparticles in ocular tissues. J Microencapsul 8 : 497-504.

Zimmer A, Mutschler E, Lambrecht G, Mayer D, Kreuter J. 1994. Pharmacokinetic and pharmacodynamic aspects of an ophthalmic pilocarpine nanoparticle-delivery-system. Pharm Res 11:1435-42. 